\title{
Optimization of a Morphing Wing Based on Coupled Aerodynamic and Structural Constraints
}

\author{
P. Gamboa* \\ Universidade da Beira Interior, 6200-358 Covilhã, Portugal \\ J. Vale \pm and F. J. P. Lau \\ Instituto Superior Técnico, 1049-001 Lisbon, Portugal \\ and \\ A. Suleman $\stackrel{\S}{-}$ \\ University of Victoria, Victoria, British Columbia V8W EP6, Canada
}

DOI: $\underline{10.2514 / 1.39016}$

\begin{abstract}
This paper presents the work done in designing a morphing wing concept for a small experimental unmanned aerial vehicle to improve the vehicle's performance over its intended speed range. The wing is designed with a multidisciplinary design optimization tool, in which an aerodynamic shape optimization code coupled with a structural morphing model is used to obtain a set of optimal wing shapes for minimum drag at different flight speeds. The optimization procedure is described as well as the structural model. The aerodynamic shape optimization code, that uses a viscous two-dimensional panel method formulation coupled with a nonlinear lifting-line algorithm and a sequential quadratic programming optimization algorithm, is suitable for preliminary wing design optimization tasks. The morphing concept, based on changes in wing-planform shape and wing-section shape achieved by extending spars and telescopic ribs, is explained in detail. Comparisons between optimized fixed wing performance, optimal morphing wing performance, and the performance of the wing obtained from the coupled aerodynamicstructural solution are presented. Estimates for the performance enhancements achieved by the unmanned aerial vehicles when fitted with this new morphing wing are also presented. Some conclusions on this concept are addressed with comments on the benefits and drawbacks of the morphing mechanism design.
\end{abstract}

\begin{tabular}{ll} 
& \multicolumn{1}{c}{ Nomenclature } \\
$A$ & $=$ wing aspect ratio \\
$b$ & $=$ wing span \\
$C$ & $=$ right Cauchy-Green tensor \\
$C_{D}$ & $=$ vehicle drag coefficient \\
$C_{D F}$ & $=$ aircraft, less wing, parasite drag coefficient \\
$C_{D W}$ & $=$ wing drag coefficient \\
$C_{L}$ & $=$ wing lift coefficient \\
$C_{L \alpha}$ & $=$ lift-curve slope \\
$C_{l}$ & $=$ airfoil lift coefficient \\
$c$ & $=$ chord \\
$D_{W}$ & $=$ total wing drag \\
$D_{i}$ & $=$ wing induced drag \\
$D_{0}$ & $=$ wing parasite drag \\
$F$ & $=$ force \\
$f$ & $=$ objective function \\
$g$ & $=$ inequality constraint \\
$h$ & $=$ equality constraint \\
$K$ & $=$ weight fraction constant \\
$L$ & $=$ lift \\
$R e$ & $=$ Reynolds number
\end{tabular}

Presented as Paper 1890 at the AIAA 3rd Multidisciplinary Design Optimization Specialists' Conference, Honolulu, HI, 23-26 April 2007; received 9 June 2008; revision received 10 December 2008; accepted for publication 22 January 2009. Copyright @ 2009 by P. Gamboa, J. Vale, F. Lau, and A. Suleman. Published by the American Institute of Aeronautics and Astronautics, Inc., with permission. Copies of this paper may be made for personal or internal use, on condition that the copier pay the $\$ 10.00$ per-copy fee to the Copyright Clearance Center, Inc., 222 Rosewood Drive, Danvers, MA 01923; include the code 0001-1452/09 and \$10.00 in correspondence with the CCC.

*Assistant Professor, Aerospace Sciences Department; pgamboa@ubi.pt. Member AIAA.

${ }^{\dagger}$ Ph.D. Student, Mechanical Engineering Department; zevale@ist.utl.pt.

¥Assistant Professor, Mechanical Engineering Department; lau@ ist.utl.pt.

${ }^{\S}$ Professor and Associate Dean of Research, Mechanical Engineering Department; suleman@uvic.ca. Associate Fellow AIAA.

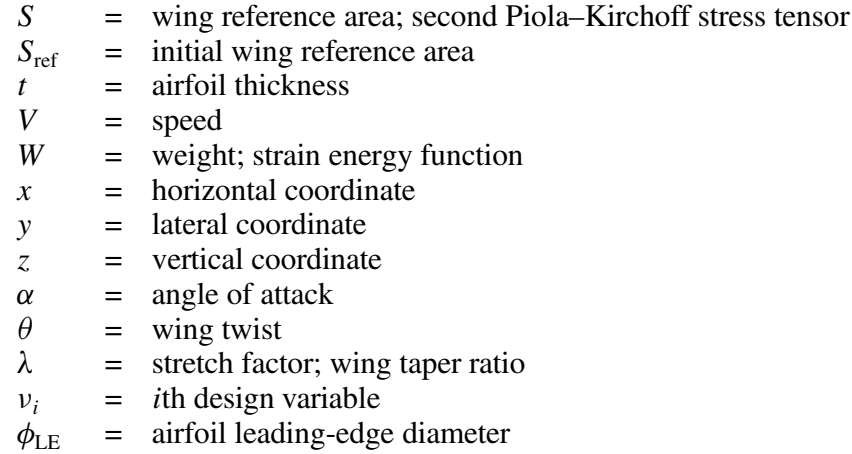

\section{Introduction}

$\mathbf{N}$ EW advances in smart materials and adaptive structures have made possible the idea of morphing airfoils or wing shapes inflight to adapt the aircraft configuration to all flight conditions. The goal is to create an airfoil or wing that will be able to reconfigure itself to give optimal performance at all stages of flight.

Some of the morphing concepts are designed to change the shape of the wing section alone, thus altering local camber, twist, and even airfoil thickness distribution. Effective roll control and drag reduction are the main goals of these morphing technologies. Conformal surface controls are more lift, drag, and power efficient than traditional hinged controls [1-4]. Twist and camber control can adjust geometric and aerodynamic twist at different flight regimes for aerodynamic efficiency. Many airfoil morphing concepts have been proposed and developed, with some being implemented experimentally on bench rigs and small unmanned aerial vehicles (UAVs); for example, the active camber variation with rotating ribs and sliding skin [5]]; the form variable flap, able to produce continuous chordwise and spanwise camber variation [6]; the airfoil morphing via bistable laminated composite structures [7]; and the airfoil morphing using actuated postbuckled, precompressed piezoelectric transducers (PZTs) for roll control []]. 
It is apparent that wing morphing gives much better improvements than is possible to obtain from airfoil morphing alone. Many different wing morphing concepts are under development. These concepts can change one or various geometric parameters of the wing, such as span, chord, camber, sweep and twist, to name just a few, to adapt its configuration to the various mission requirements. Wing morphing concepts involve more radical shape changes than those of airfoil morphing. Some of these concepts are the inflatable wing with new materials for roll control (using nastic structures, bump flattening, or trailing-edge deflection $[9,10])$; the variable-span wing [11] with pneumatic telescopic spars [12,13]; the hyper-elliptic wing with variable-camber span that uses a quaternary-binary link configuration mechanism, shape memory alloy (SMA)-based tendons [14], or tendon-actuated compliant cellular trusses made of octahedral unit cells [15] for actuation [16]; the biologically inspired aeroservoelastic control SMA threads or torque rods for high roll control authority in micro air vehicles [17-20]; and the wing with variablecant winglets for roll control $[21,22]$. Two concepts under the Morphing Aircraft Structures Program that have seen enormous developments with full-scale models being built are the folding wing concept of Lockheed Martin, with efficient loiter and fast dash configurations [23-27], and the bat wing design of NextGen, with high lift and efficient loiter configurations [28-30].

Because of radical shape and size changes that may result in the morphing process, parts of the aircraft, other than the wings, may be required to sustain morphing in order to maintain stability and effective control. One such fully adaptive aircraft configuration was developed to be used as an experimental testbed for aerodynamic modeling and flight control [31]. The morphing capabilities of the adaptive planform vehicle experiment design are variable sweep, tail extension, span extension, and wing twist.

A wide range of adaptive materials [32-34], such as shape memory materials [35,36], macro fiber composites [37], flexible matrix composites [3] , or specially designed skin materials that exhibit high in-plane flexibility while keeping out-of-plane stiffness [39] can be used to accomplish some of the morphing concepts.

In addition to all the aforementioned advances, improvements in computational fluid dynamics, optimization techniques, and multidisciplinary design approaches have also increased the ability of engineers to improve the designs of aircraft. Since the late 1970s, when Hicks and Henne [40] published one of the first papers on aerodynamic shape optimization, aerodynamic shape optimization has become a very active area of research, and several innovative methods for the aerodynamic shape optimization of airfoils [41-49], wings [50,51], full aircraft configurations [52-54], and even aerostructural optimization of full aircraft configurations [55-62], including the new blended-wing-body transport aircraft [ $\overline{63}-\overline{68}$ ], have been published. Different optimization algorithms, generally gradient-based and evolutionary, and different fidelity analysis tools have been used to solve these problems according to the design requirements. In these papers, single, multipoint or robust aerodynamic shape optimization problems have been solved in order to obtain a fixed optimal aircraft configuration. However, the new advances in morphing mechanisms allow aircraft performance to be further increased by obtaining the optimal aircraft configuration at different stages of flight, and then use these morphing mechanisms to change aircraft configurations in-flight to achieve an all-stage optimal performance. Optimization of morphing airfoils has also been performed for various applications: enhanced performance of a UAV in some flight conditions [69]; increased endurance using the variform concept, whereby the airfoil reduces thickness as the fuel held inside the wings is burnt [70]; variable-camber airfoil, in which the upper surface is moved up and down by means of PZT plates to adjust the maximum lift-to-drag ratio to the required flight speed [71]; effective yaw control through bumps on the upper surface of the airfoil, for which minimum actuation energy is required [72]; airfoil capable of splitting into two parts to increase wing area for loiter flight $[\underline{73}, 74]$; and airfoil designed not only to reduce drag but also the morphing actuation energy [75].

Other important aspects of morphing wing design are the weight penalty and the actuation power that the morphing mechanisms require in order to perform their tasks; as well as the integration of aerodynamics, mechanism structure, and actuation design in the optimization approach [76]. These aspects have important effects on the optimal final morphing designs. Based on optimized finite element (FE) models of a wing at different geometric states, wing weight equations and methods to size morphing aircraft have been developed [77-80]. Also, morphing strategies according to mission have been addressed [81-83].

The purpose of introducing morphing capability in an aircraft is to improve one or various performance parameters without significant penalty in the remaining parameters. For example, if a morphing aircraft can operate with lower drag when compared with a fixed wing aircraft in some (or every) flight condition, then the morphing aircraft will have improved performance parameters (such as fuel consumption and maximum speed) that can also be traded off for extra payload, extended range, or extended loiter time.

In this paper, an aerodynamic shape optimization code coupled with a structural morphing model is used to obtain a set of optimal wing shapes at different flight speeds of a light UAV to gain insight to the capabilities of the morphing concept and obtain performance improvements over the complete flight envelope of the UAV. Sec. II describes the UAV characteristics. Sec. III presents the morphing wing concept, the aerodynamic optimization method, and the structural conceptual design of the morphing wing. Sec. IV presents the results obtained from the optimization of the wing at different flight speeds, and the results obtained from the coupled aerostructural analysis, followed by a discussion on how they affect the performance of the UAV. Finally, in the conclusions, the results are analyzed in order to assess the performance of the morphing mechanisms and quantify the advantages of having such a morphing capability.

\section{Wing Requirements}

A small experimental UAV that has been developed for studying adaptive aeroelastic structures [33] is used as the design platform. Its original wing structure is made of balsa wood ribs, a balsa wood torsion box, and carbon-fiber spars. The total weight of the wing is $15 \mathrm{~N}$. The aim is to design a morphing wing that, over the same speed range and for the same takeoff weight, will have less drag. Any increase in the structural or morphing mechanism weights of the wing is reduced from the fuel and payload weight in order to keep the total weight constant.

\section{A. Unmanned Aerial Vehicle Characteristics}

The main geometric characteristics of the UAV to which the wing will be fitted are a takeoff weight $W$ of $100 \mathrm{~N}$, a constant chord $c$ of $0.33 \mathrm{~m}$ across the span, a wing area $S$ of $0.792 \mathrm{~m}^{2}$, the wing span $b$ of $2.4 \mathrm{~m}$, and the wing aspect ratio $A$ of 7.273. From $c$ and $S$, one can calculate the wing span $b$ and the wing aspect ratio $A$. Figure 1 illustrates the UAV, showing the high wing, two-tail boom configuration. The central part of the wing supports the two-tail booms and, therefore, will not be changed in the design optimization. The UAV wing uses the Wortmann FX 63-137 airfoil that provides a high maximum lift coefficient and a lightweight structure due to its comparatively high relative thickness. This UAV has a cruise speed

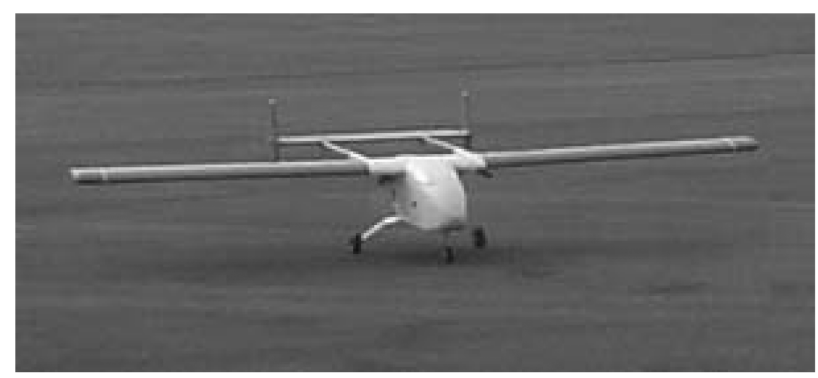

Fig. 1 Experimental UAV under study. 
of $30 \mathrm{~m} / \mathrm{s}$ but, due to its large wing size, it exhibits good low-speed performance that was a driving factor in the original vehicle's design.

In the aerodynamic analysis of the UAV, the drag coefficient of the vehicle without wing $C_{D F}$ is assumed constant, with a value of 0.02 , and the drag coefficient of the wing $C_{D W}$ is a function of wing geometry, angle of attack (AOA), and speed, for a total lift equal to the vehicle's weight. Equation (1) shows the drag coefficient representation, taking the original wing area as the reference area $\left(S_{\text {ref }}=0.792 \mathrm{~m}^{2}\right)$. It is assumed that only the wing contributes to lift:

$$
C_{D}=C_{D F}+C_{D W}\left(S / S_{\text {ref }}\right)
$$

The UAV is fitted with a small gasoline engine with $1800 \mathrm{~W}$ $(2.4 \mathrm{hp}$ ) power at $12,000 \mathrm{rpm}$, driving a $0.38 \mathrm{~m}$ diameter fixed-pitch propeller.

\section{B. Performance Requirements}

The goal of this work is to have a UAV for which the wing can reconfigure itself in-flight to maximize its performance at a given flight speed. The UAV should be able to fly from 15 to $50 \mathrm{~m} / \mathrm{s}$ with reduced fuel consumption over this speed range when compared with the UAV fitted with the original wing. The flight altitude is kept constant at sea level.

\section{Wing Design}

Minimizing drag is a major concern in aircraft design. This is particularly true in the design of a small UAV because its reduced size limits the quantity of fuel carried and hence its range and endurance. Thus, the definitions of the most suitable morphing strategy for minimizing drag and the structural means to produce the shape changes in the aircraft wing are very important

A tool for designing the wing was developed by combining in-house computer codes using well-established algorithms for aerodynamic analysis and optimization with a commercial program for structural analysis. More advanced design approaches have been proposed $[76,80,81]$, but the algorithms implemented enabled fast calculations on a single-processor computer and are suitable for optimization work for conceptual and preliminary design evaluation. All completed wing aerodynamic shape optimization cases required between 2 and $8 \mathrm{~h}$ of running time on a single $2.4 \mathrm{GHz}$ Pentium 4 CPU.

\section{A. Morphing Concept}

The morphing concept is based on three variable wing geometric parameters: variable span, variable chord, and variable airfoil shape. These three variables allow the change in wing-planform shape and size, as well as airfoil thickness and shape. All of these parameters directly affect wing drag in all or some of the flight conditions. The concept presented does not use adaptive materials; it uses an adaptive internal structure built with conventional materials that are covered with a flexible skin for the aerodynamic shape. Unlike the NextGen bat wing, which has a sweep/chord variation coupling that makes its flexible skin withstand in-plane deformation without altering the airfoil thickness, this concept changes the thickness by out-of-plane actuation on the skin.

Therefore, in this study, the wing chord is allowed to vary between 1 and 1.5 times its lower limit value; the span is allowed to vary between 1 and 1.4 times its lower limit value; and the airfoil thickness is allowed to vary between 1 and 1.8 times its lower limit value. This set of geometrical constraints is suitable for an optimization process with drag minimization as the objective function. Once the wing optimal shape is determined, within the geometrical limits, for a set of flight conditions, a structural model of the morphing mechanism can be built and a coupled aerostructural analysis scheme can be set up to estimate wing drag performance and the effects of the wing morphing on other aerodynamic parameters.

The proposed mechanism tries to produce both chord and span morphing, while allowing changes in the wing airfoil, either by simply scaling the wing airfoil according to the new chord or by actually changing the complete geometry of the airfoil. It consists of a telescopic rib that is actuated by a rotational device that drives screws, causing displacement on the outer skin of the wing section. The amount of displacement in each station of the rib is determined by the screw pitch and the allowable number of rotations that the screw can take at that station.

The shape of the airfoil (chord length and thickness distribution along the chord) must therefore be known previously to the assembly of the mechanism, and this is why the optimization process is needed before the design of the morphing mechanism is completed. Although the mechanism concept does not represent the optimized airfoil with enough accuracy, this approach is used to identify the optimal shapes. Future developments may improve the actual shape achieved by the mechanism. With this mechanism, the shape of the airfoil has a direct relation with the chord and span length, and so the optimized shape must be found. If a linear relation between the chord length and the airfoil shape can be used as an approximation, the number of actuators needed to deform the wing skin could be reduced through the use of screws or gears in order to transmit the motion from moving rib parts.

\section{B. Aerodynamic Optimization}

The objective of the morphing wing design is to minimize the wing drag $D_{W}$ at all speeds when lift $L$ equals the aircraft weight. To achieve this, a tool that searches for the best airfoil geometry and the best wing-planform shape is used, taking geometric constraints imposed by the limitations of the morphing technology into account. The aerodynamic analysis is done in two steps. First, the twodimensional (2-D) aerodynamic coefficients as functions of AOA and Reynolds number $R e$ at specified wing sections across the span are obtained using the solver of the XFOIL code [83]. In XFOIL, the steady Euler equations in integral form are used to represent the inviscid flow, and a compressible lag-dissipation integral method is used to represent the boundary layers and wake. The entire viscous solution (boundary layers and wake) is strongly interacted with the incompressible potential flow via the surface transpiration model that permits proper calculation of limited separation regions. Results from XFOIL have been compared against experimental data with good agreement [84]. The airfoils are represented by $b$-spline control points in a similar fashion, as is described in Secanell et al. [69], but instead of using the control points to define the airfoil surface, one uses the control points to define the airfoil camber line and the airfoil thickness distribution that are combined to give the airfoil surface (see Fig. 2). Then, a nonlinear lifting-line method [85] algorithm is used to obtain the lift distribution and the induced drag. Parasite drag is obtained by integrating airfoil drag over the wing span. The wing is represented by the chord and incidence at specified sections along the semispan. The sections' aerodynamic information comes from the previous step. Low-speed wings do not require any sweep in most cases. Also, for the UAV under study, the high wing position gives the

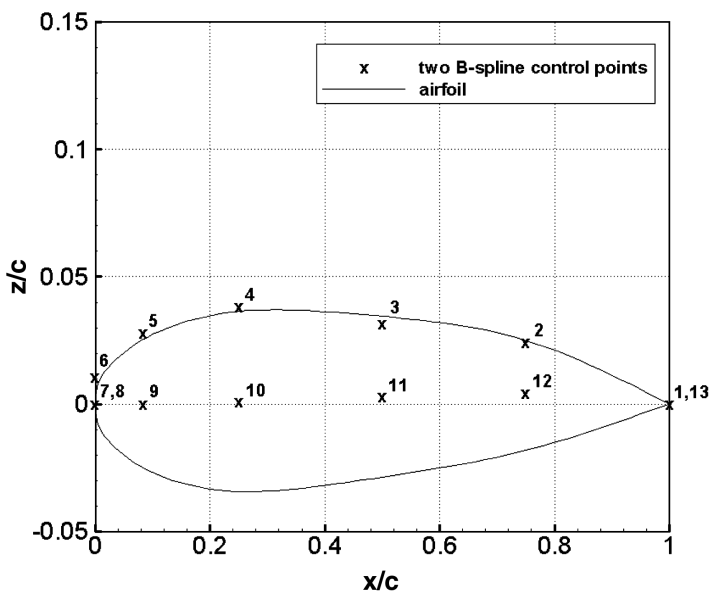

Fig. 2 Camber line and thickness distribution of the airfoils, and corresponding airfoil geometry. 


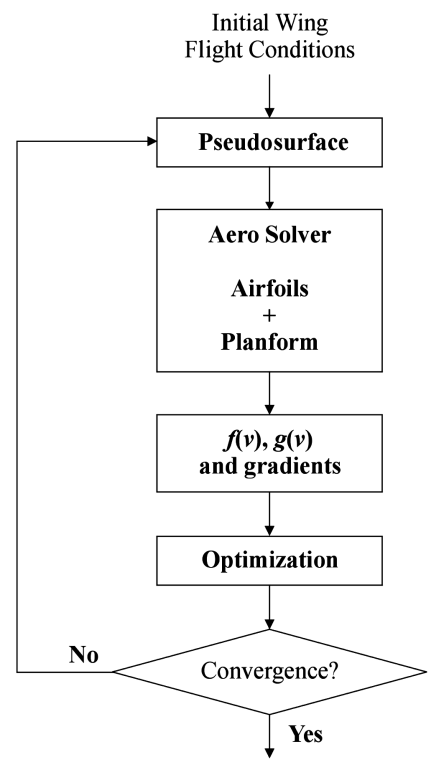

Fig. 3 Flowchart of the wing aerodynamic shape optimization design tool.

necessary lateral stability, ruling out the need for any wing dihedral. Because of those two factors, the simple lifting-line method was selected to calculate the three-dimensional aerodynamic coefficients of the wing. The classical Prandtl lifting-line theory assumes a linear variation of $C_{l}$ with AOA. However, in practice, as the AOA approaches and exceeds the stall angle, the lift curve becomes nonlinear. Therefore, there are practical reasons for extending Prandtl's classical theory to account for a nonlinear lift curve. The elements of the lifting-line theory lend themselves to a purely numerical solution that allows the treatment of nonlinear effects. This method can be applied to a general planar finite wing of given planform and geometric twist with different airfoil sections at different spanwise stations. Data for the lift curves and parasite drag curves of the airfoil sections, including the nonlinear regime, are obtained from the airfoil aerodynamic analysis tool. The numerical iterative solution for the finite wing properties are described in detail in [85]. The method implemented has been shown to compare reasonably well with experiment, even near the stall [85]. Convergence of the lift distribution for a wing, with the chords varying in a nonlinear fashion along the span, has been achieved with less than 30 semispan airfoil stations [84]. By using this aerodynamic analysis approach, one assumes that the wing remains planar after loading, thus requiring enough bending stiffness from the wing spar. Also, spanwise loads are not available.

The aerodynamic shape optimization is carried out with the sequential quadratic programming (SQP), constrained optimization algorithm DONLP2 [86]. The purpose of the DONLP2 algorithm is the minimization of a (in general, nonlinear) differentiable real function subject to (in general, nonlinear) inequality and equality constraints. Numerical techniques, such as DONLP2, generally assume that the design space is convex, continuous, and unimodal. Because of this, numerical techniques tend to converge quickly to a local optimum close to the initial design point. Thus, the effectiveness in finding a global optimum is highly dependent on the topology of the design space and the choice of the initial design point. Nonetheless, SQP has been shown to produce good results [48,49].

The gradients of the objective function and constraints are a requirement of any gradient-based optimization algorithm. In this work, the gradients are computed using forward finite differences that enable the problem of finding the gradients to be treated as a black box. Therefore, it can be used with any fluid flow solver because it does not involve changes in the solver's code.

The aerodynamic shape optimization problem can be stated as

Minimize with regard to $v_{i}$

$$
f(v)=D_{W}(v)
$$

subject to

$$
[h(v)=0] \quad g(v) \geq 0
$$

where the design variables $v$ may be flight and/or geometric parameters, and the equality $h(v)$ and inequality $g(v)$ constraints may be lift and/or geometric parameters.

Figure $\underline{3}$ shows a flowchart that illustrates the implementation of the aerodynamic shape optimization tool. The code can be summarized as follows:

1) Create the airfoils using the $b$-spline approach.

2) Create a pseudosurface with airfoils and wing-planform geometric information.

3) Compute objective function $f(v)$ and constraints $h(v)$ and $g(v)$ of the optimization problem using the aerodynamic solve.

4) Compute gradients of objective function and constraints using forward differences.

5) Solve the optimization problem using the SQP method.

6) If the optimization problem has converged, stop; if the optimization has not yet converged, continue.

7) Use the new design variables to create new airfoils and planform geometry, and go to step 3.

\section{Structural Conceptual Design \\ 1. Skin Material}

To achieve the desired shape changes for the morphing wing, the skin material has to allow high strains, which is not the case with the materials usually used in conventional aircraft. Therefore, rigid materials, such as metals or high-stiffness/low-strain polymer membranes, were ruled out. Rubber materials and other polymers could be considered as candidates, including new smart materials such as shape memory polymers. Nevertheless, natural rubber was chosen to be the skin material in this conceptual design, due to its availability and low price, and the goal of this project, which is to prove the morphing concept without much concern about cyclic fatigue or environmental hazard. The use of a shape memory polymer was initially considered, but the increase in complexity of the morphing system due the heating requirements and the elasticperfectly-plastic behavior of such material makes its shape memory properties, at least, unusable when the wing is loaded.

\section{Chord Extension Mechanism}

The purpose of this mechanism is not only to increase the chord at a wing section but also to discretize the airfoil and allow changes in airfoil thickness at some control points. In this work, it is considered that the mechanism divides the airfoil into six different sections along the chord: three of them being evenly spaced from the quarter-chord to the leading edge, and the other three being evenly spaced from the quarter-chord to the trailing edge.

A total of 10 control points are considered for thickness changes, five on the upper surface of the airfoil and five on the lower surface, paired at the same chordwise coordinate. Leading-edge and trailingedge points are not considered for thickness changes. As the mechanism expands, the chordwise relative positions of the control points are maintained. Figure 4 illustrates the design of the rib expansion mechanism parts. It includes a threaded core (the threads are not shown in Fig. 4a) that is rotated by means of an actuator, and it produces translational movement of the remaining mechanism parts. As these parts move, vertical screws are driven to change the thickness of the airfoil at the control points. It is assumed that suitable actuators can be found to rotate the core of the rib extension mechanism. No detailed actuation solution was devised because, at this stage, only preliminary studies have been performed.

\section{Span Extension Mechanism}

The span extension mechanism is intended to stretch the wing skin and maintain the even distribution of the rib expansion mechanisms along the span of the wing. This is done by pushing the spars out of the fuselage. Because the ribs must slide along the spars, there cannot be only one solid spar; therefore, the spars' overall stiffness can be 


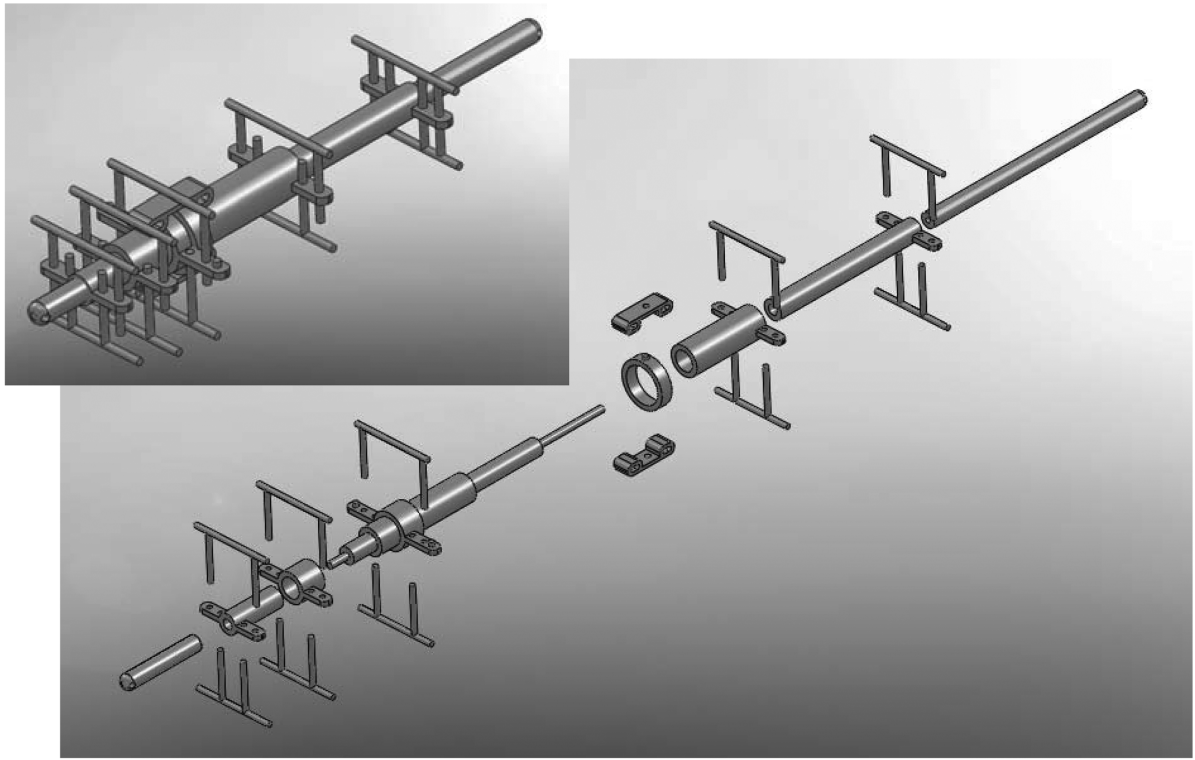

a)

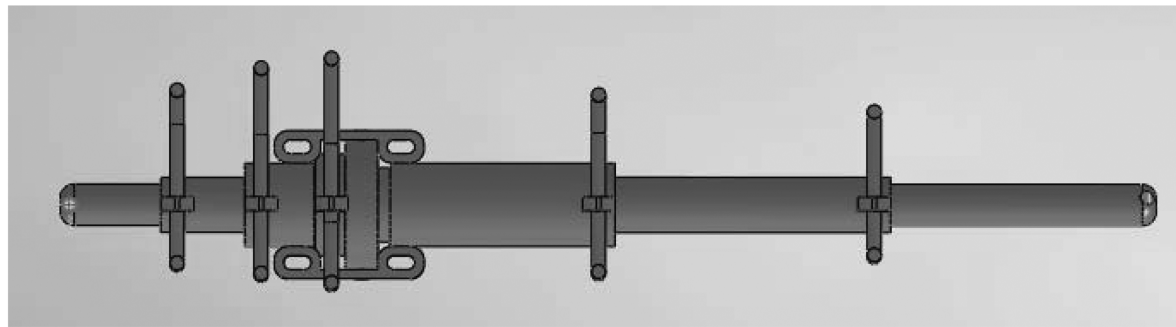

b)

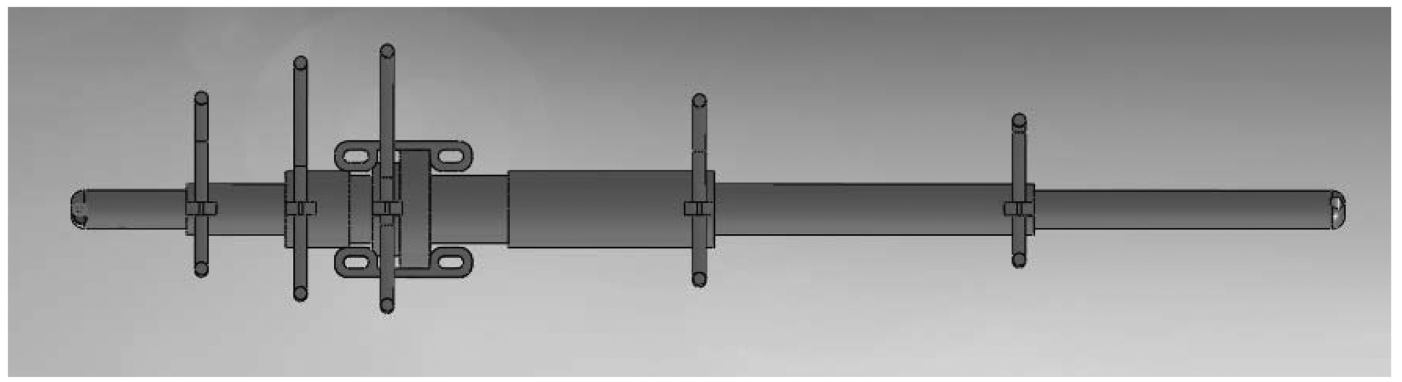

c)

Fig. 4 Rib extension mechanism (not to scale): a) normal and exploded views b) retracted and c) extended.

affected, depending on how the multiple spars are constrained. By using the appropriate dimensions and number of plates between the ribs, the mechanism shown in Fig. 5 will maintain the even spacing of the ribs along the wing span. Another possible way to maintain the equal spacing of the ribs would be to introduce some spring elements connecting the ribs. Rubber bands are an example of elements that might be used. Again, at the current stage of this work, no particular actuation solution was devised for pushing the spar elements out of the fuselage.

\section{Wing Structural Finite Element Model}

The FE structural model of the wing was built not only to perform the coupled aerodynamic-structural analysis but also to assess the wing deformation forces involved in such a structure. Therefore, the model is required to allow the application of aerodynamic loads on the wing deformable skin and simulate some of the moving parts of the morphing mechanism in such a way that relevant forces and moments acting on it can be obtained.

Skin Material Model. Rubberlike materials can be modeled in a number of ways when a FE model is applied, traditionally using a strain energy function dependent on only deviatoric deformations. A variety of strain energy functions are supported by ANSYS $®$ $[87,88]$, the commercial structural analysis program used, and the user can choose the one that better fits the material data that are being modeled. In the present case, the Yeoh model [89-92] was used.

Also, some conformal elements were added to the model, to help reduce the skin deformation between the ribs, that were not planned in the initial mechanism conception. These conformal elements were modeled as elastic strings with high Young's modulus (see Figs. $\underline{6 c}$ and 6d).

Skin Material Model. For simplicity, the rib mechanism's rotating core and the span extension mechanism parts were assumed to be rigid enough to support all deformation loads with negligible deformation of their own; therefore, they are not modeled. This statement is true if the mentioned parts are sized according to the loads they are subject to, which can be done after the analysis. Figure 7 illustrates the type of elements used in the FE model and where they are used.

Displacements and Loads. Structural displacements are applied at specific nodes that are connected to the mechanism parts using MPC184. The FE software solution enables one to assess the reaction 

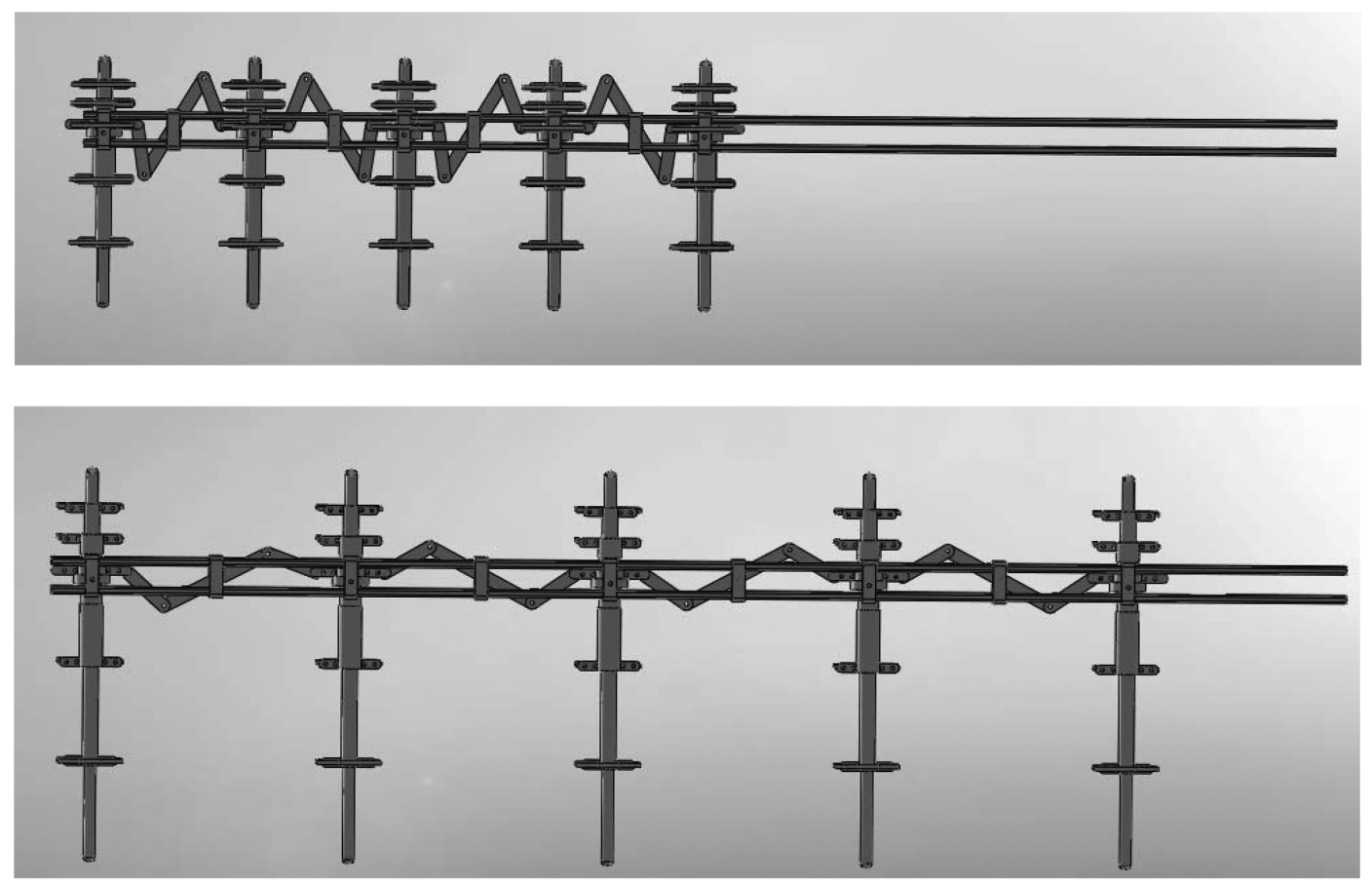

Fig. 5 Spar extension mechanism (not to scale): retracted (top) and extended (bottom).
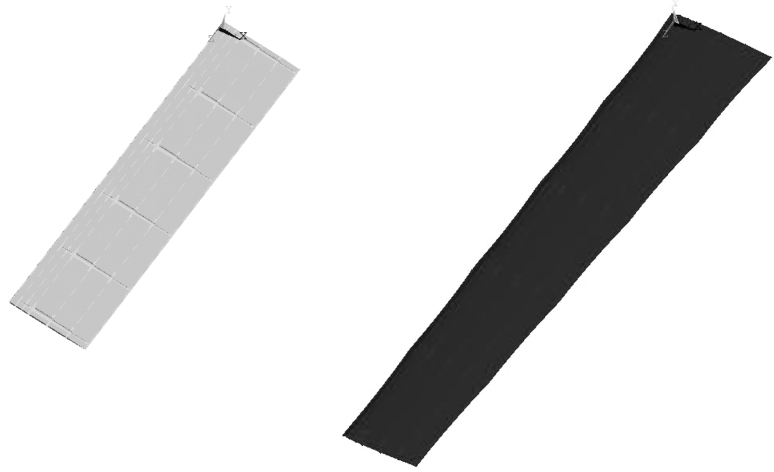

a)

b)

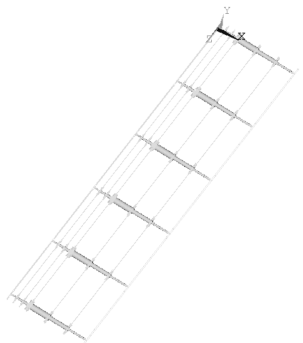

c)

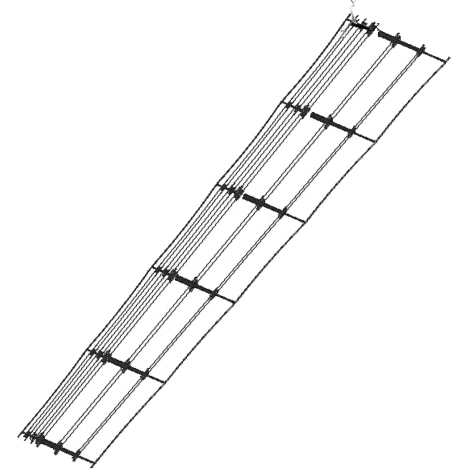

d)

Fig. 6 FE wing model: a) skin and mechanism, b) deformed skin and mechanism, c) mechanism, and d) deformed mechanism.

forces and moments in these nodes, allowing the assessment of the structural requirements for the morphing mechanisms.

Aerodynamic loads are applied directly to the skin nodes as forces in the Cartesian reference frame. These forces were calculated by integrating and dimensionalizing the pressure coefficient (normal to surface) and the friction coefficient (tangent to surface) obtained from the aerodynamic analysis over the adjacent area, between the

previous and following sections, of all stations considered (50 in total). Pressure coefficients and friction coefficients were obtained for each wing section at every panel node by running the 2-D airfoil analysis program for the local AOA obtained from the lifting-line analysis. In doing this, it was assumed that the force component in the $y$ direction (spanwise) was negligible, because the aerodynamic analysis method is not capable of calculating it. Because the aerodynamic model mesh is different from the mesh used for the structural analysis (which is more refined), forces in a particular location are evenly distributed in the surrounding skin nodes.

Solution Convergence Study. A simple convergence study using a section of the wing was performed to assess the suitability of the FE model mesh. This study revealed that the refinement of the mesh could solve convergence problems, but deformation forces and moments' results did not differ significantly from a less refined mesh to a more refined mesh, mostly because the least refined mesh that allows convergence of the problem is already highly refined. Therefore, to reduce computation time requirements, the least refined mesh was chosen to be used in the structural analysis, and more refined meshes were used whenever convergence problems occurred. A mesh size of 344,830 elements was used, from which 271,360 were used for the skin modeling, 39,558 were used for mechanism parts modeling, 21,000 were used for elastic strings modeling, and the remainder were used for imposing translation movement on the modeled mechanism parts (contact and multipoint constraint elements).

Note on the Use of Initial Stretch of the Skin. To resist and transmit aerodynamic forces to the structure, the wing skin acting as a membrane must be stretched before the loading. However, the rubber material model used in this work becomes unstable at high stretches, say $\lambda \geq 1.7$; that means that for a fully deformed wing, a high initial stretch would cause model convergence problems. Therefore, the initial stretch was adjusted to allow the full analysis of the wing for each flight condition, bearing in mind that real rubber materials can stretch up to $100 \%$ and more, and that this action will cause error in the prediction of deformation forces. The initial stretch varies from $5 \%$ for configurations with the highest span value to $20 \%$ for configurations with the lowest span.

\section{Aerodynamic Optimization and Coupled Aerostructural Analysis}

The approach used to estimate the morphing wing drag and structural requirements is illustrated in Fig. $\underline{8}$. At a given flight 


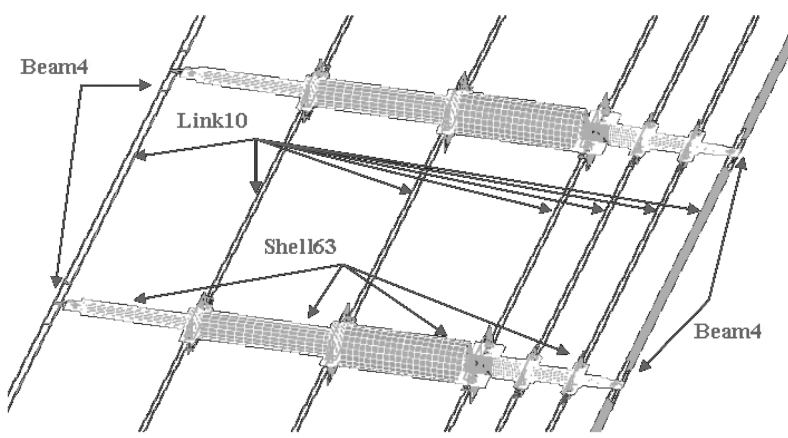

a)

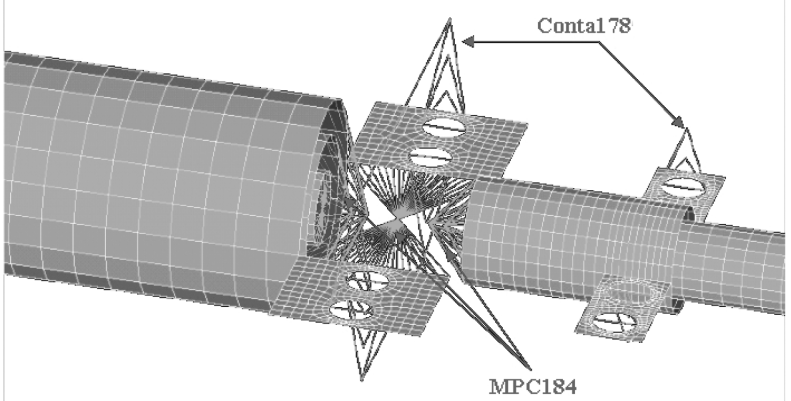

b)

Fig. 7 Element types used in the FE wing model: a) Beam4, Shell63, and Link10; and b) Conta178 and MPC184.

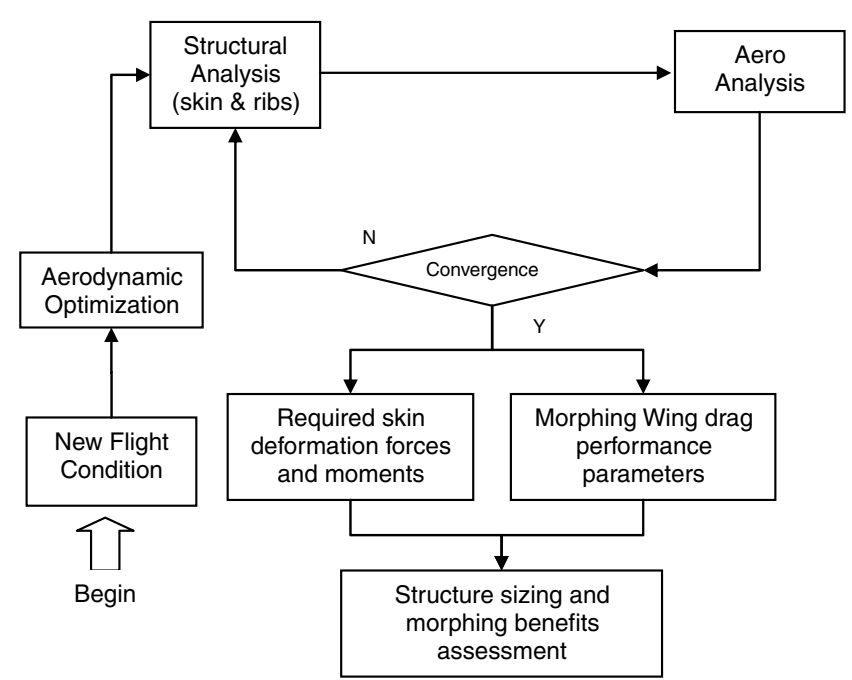

Fig. 8 Flowchart of coupled aerostructural analysis for an optimum morphing wing at different flight speeds.

condition and aircraft weight, the aerodynamic optimization tool optimizes the wing shape and passes it together with the aerodynamic loads to the structural model. Here, the structural control points of the morphing ribs are made coincident to the aerodynamic control points, and the aerodynamic loads are distributed to the skin FE model nodes. Then, the structural analysis is carried out with the control points fixed, and the deformation of the skin is obtained. In the next iteration, the new wing shape is passed back to the aerodynamic solver and new loads are computed. The process is repeated until convergence is achieved. When all flight conditions are analyzed, the most critical loads on the rib control points will be used to size the mechanical parts and structural components of the internal mechanism. At the moment, weight and power requirements are not fed back to the optimization phase.

The convergence criterion for this coupled problem is based on the aerodynamic loads, because only these loads vary and cause different deformations on the structure. Once the aerodynamic loading is nearly constant, the deformed wing has its stationary shape for the current flight condition. Therefore, convergence is obtained when the following conditions are satisfied:

$$
\begin{aligned}
& \frac{\sum_{j}^{n}\left|1-F x_{j}^{i-1} / F x_{j}^{i}\right|}{n} \leq 10^{-2} \\
& \frac{\sum_{j}^{n}\left|1-F z_{j}^{i-1} / F z_{j}^{i}\right|}{n} \leq 10^{-2}
\end{aligned}
$$

where $i$ is the iteration number, $F x_{j}$ and $F z_{j}$ are the aerodynamic forces in the Cartesian frame of reference evaluated at the $j$ th point, and $n$ is the number of points in which the aerodynamic forces are evaluated. This criterion corresponds to an average relative error of less than $1 \%$ in the forces.

\section{E. Morphing Concept Limitations}

Some limitations imposed by the morphing concept described in this work are due to the morphing mechanism not being able to represent the optimized wing shape with enough accuracy. The main differences between the optimized shape and the deformed wing shape consist of the following:

1) The mechanism is unable to provide the ribs with a smooth airfoil shape with nice curved lines between control points.

2) The fixed leading-edge radius is too small at low speeds because the maximum thickness and camber positions move forward and the first control point stands out creating a good place to trigger separation.

3) The mechanism is unable to sufficiently change the airfoil camber line for low speed flight.

4) The use of a flexible skin implies that the aerodynamic loading may deform the skin significantly which alters the aerodynamic characteristics of the airfoils.

Because the mechanism is based on screw motion, displacements of mechanism parts will have linear relationships with the displacement actuators; therefore, a wing-section chord that has a strong nonlinear relation with other wing geometrical parameters (e.g., wing span variation) will suffer from linear approximation errors unless a specific actuator for that section is used, thus increasing wing weight.

\section{Results and Discussion}

The numerical results of this work are very promising as to the extent of performance improvements that can be achieved with the morphing concept proposed.

In Sec. IV.A, the results of the aerodynamic optimization are presented, and the particular characteristics of the procedure are explained. Wing optimized planform area and airfoil geometry results for different flight speeds are shown. Sec. IV.B shows the solutions of the coupled aerodynamic-structural analysis for the flight conditions for which the analyses were completed. Differences between the optimized shape of the morphing wing and the actual mechanism-deformed morphing wing solution are pointed out, and their effects on aerodynamic performance are discussed. In Sec. IV.C, performance comparisons between initial wing, optimized morphing wing, and mechanism-deformed morphing wing are shown; and overall morphing benefits are discussed. Future possible mechanism improvements are addressed.

\section{A. Aerodynamic Optimization Results}

The existing UAV wing is analyzed first with geometric characteristics of the UAV and the Wortmann FX 63-137 airfoil. Then, two optimized fixed wings, with some empirical weight information included in the analysis, are designed for the cruise 


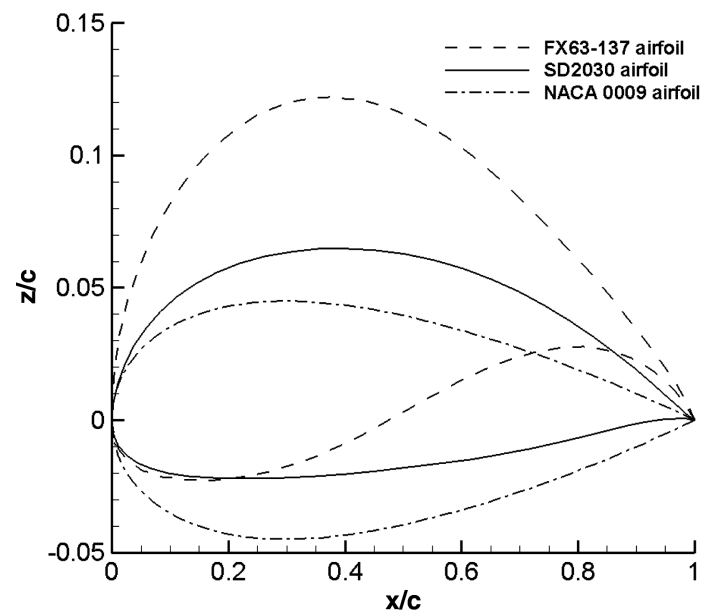

a) speed of $30 \mathrm{~m} / \mathrm{s}$ : one without any low-speed requirement and another with a stall-speed requirement. Finally, the morphing wing is optimized for all speeds, and the results are compared with the other cases. In the XFOIL analysis, a power $n$ of six in the boundary-layer envelope $e^{n}$ transition criteria was chosen because it gave better results when compared with experimental airfoil aerodynamic data [83].

\section{Original Wing}

The only design variable in this case is the AOA. All geometric parameters are constants. The aim of the analysis is to find the AOA that results in the required wing lift of $100 \mathrm{~N}$ (i.e., $L=W$ ).

The Wortmann FX 63-137 airfoil, which has a relative thickness of $13.66 \%$, is shown in Fig. 9a. The results of the original wing are shown in Fig. 10. The negative AOA at cruise speed clearly shows that the wing with the Wortmann FX 63-137 airfoil is oversized for this flight condition but, on the other hand, allows the UAV to have a low stall speed.

\section{2. $\quad$ Optimized Fixed Wing}

This fixed wing optimization problem is presented in order to 1) demonstrate that a morphing wing is important if one wants to obtain performance improvements over a wide range of speed regimes, and 2) have an optimized fixed wing to compare with the morphing wing concept presented, because the original wing is oversized for the performance required.

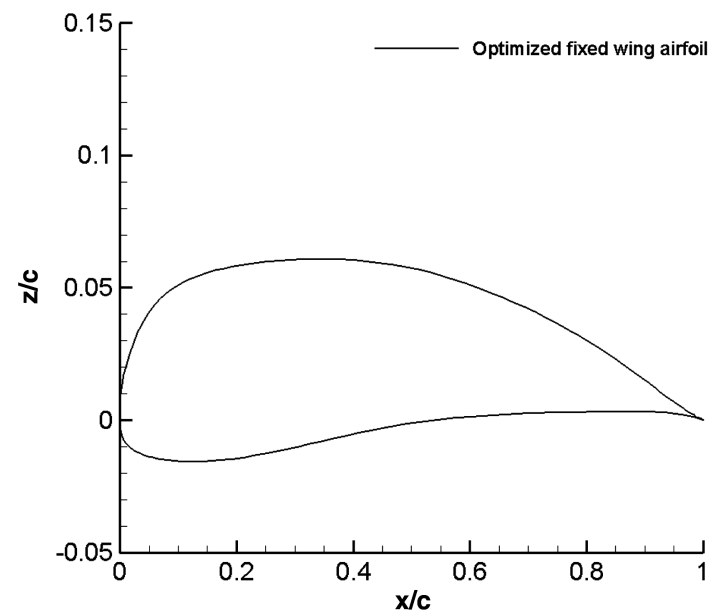

b)
In this optimization problem, the chord is limited to a minimum of $0.1 \mathrm{~m}$ to avoid excessively high aspect ratios, and a minimum value of $1 \%$ is imposed on the leading-edge control point of the airfoil. The optimization problem is stated as follows, in which all lengths are in meters, angles are in degrees, and speeds are in meters per second,

Minimize with regard to $v_{i}$

$$
D_{W}=D_{W}\left(v_{i}, V\right) \quad(i=1-16 \quad V=30)
$$

subject to

$$
\begin{array}{ccc}
L\left(v_{i}, V\right)=W & (V=30) \quad L\left(v_{i}, V\right) \geq W \quad(V=15) \\
2.0 \leq v_{1} \leq 3.4 & 0.10 \leq v_{2} \leq 0.33 \quad 0.10 \leq v_{3} \leq 0.33 \\
-4 \leq v_{4} \leq 0 & -5 \leq v_{5} \leq 15 \quad v_{11} \geq 0.01 \quad v_{j} \geq 0 \\
(j=12-16)
\end{array}
$$

where

$$
\begin{array}{ccc}
v_{1}=b \quad v_{2}=c_{\text {root }} & v_{3}=c_{\text {tip }} \quad v_{4}=\theta_{\text {tip }} \quad v_{5}=\alpha \\
v_{j}=\left(z_{k} / c\right)_{\text {control }} \quad(j=6,16 \quad k=1,11)
\end{array}
$$

In the design optimization problem of the fixed geometry wing, three wing sections were specified to represent the wing planform: one at the root, one at $0.2 \mathrm{~m}$ from root, and another at the tip of the wing. The airfoil analysis tool calculates the aerodynamic coefficient curves of the airfoil at these sections and interpolates elsewhere. The wing semispan was divided into 50 sections for the lifting-line
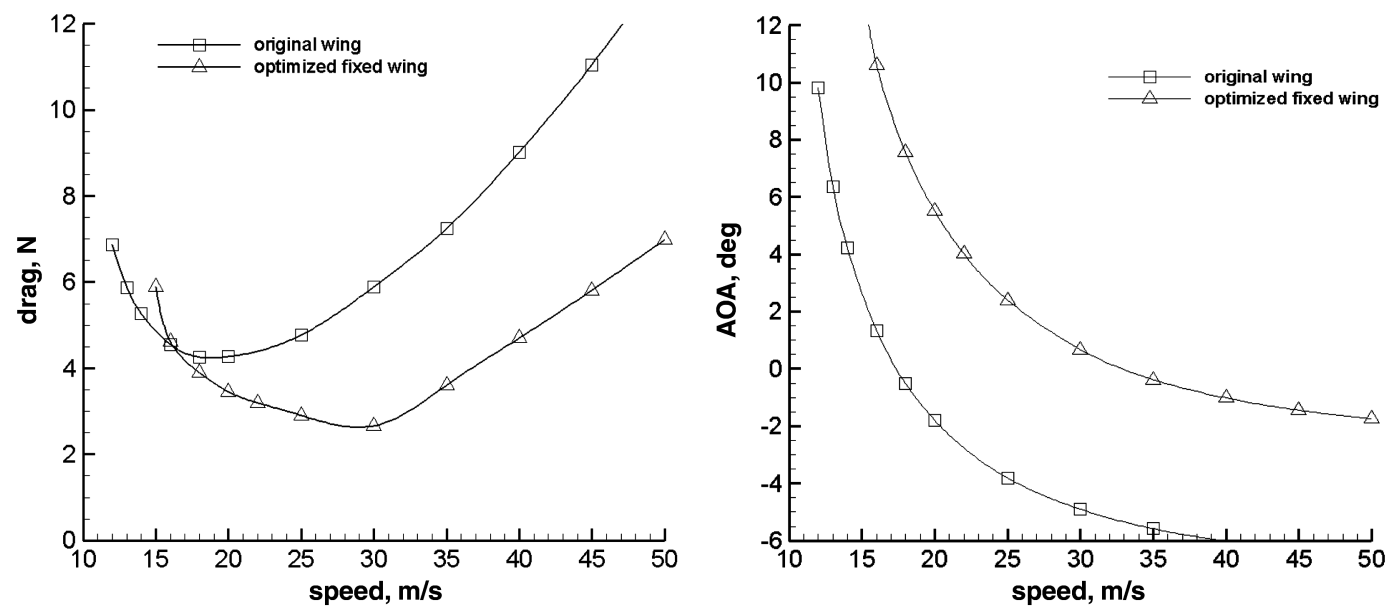

a)

b)

Fig. 10 Aerodynamic results for the fixed wing optimization problem: a) drag and b) AOA. 
Table 1 Weight and geometric characteristics of the optimized fixed wing

\begin{tabular}{lccccccccr}
\hline \hline Wing & $W, \mathrm{~N}$ & $S, \mathrm{~m}^{2}$ & $c, \mathrm{~m}$ & $b, \mathrm{~m}$ & \multicolumn{1}{c}{$A$} & $\lambda$ & $t / c, \%$ & Camber, $\%$ & $\theta,^{\circ}$ \\
\hline Original & 100.00 & 0.792 & 0.330 & 2.400 & 7.27 & 1.00 & 13.66 & 5.79 & 0.00 \\
Optimized from SD-2030 & 106.01 & 0.548 & $0.219-0.144$ & 3.023 & 16.69 & 0.66 & 7.27 & 2.82 & -0.43 \\
\hline \hline
\end{tabular}

analysis. The airfoils were discretized by using the 2-b-spline method, representing the thickness distribution and the camber distribution, with the 11 control points that are used as design variables placed at $0 c, 0.05 c, 0.2 c, 0.5 c, 0.8 c$, and $0.95 c$. A total of 150 panels, distributed in the full cosine form, were used in the airfoil analysis.

The initial design in this optimization problem is a rectangular wing with a chord length of $0.1 \mathrm{~m}$ and a span of $2.4 \mathrm{~m}$. The wing has no twist and is set at an AOA so that the resulting lift value equals the weight of the aircraft. The chord is allowed to change at the root and tip, creating a trapezoidal wing. Linear geometric twist is also a design variable, as well as the span. The only two geometric constraints imposed were a maximum span of $3.4 \mathrm{~m}$ and a minimum value of $0.001 \mathrm{~m}$ for the abscissa of the control point, that represents the thickness distributions placed at $0.95 c$. In this design, empirical weight information for the wing, the tailplane, and the vertical tail was introduced to allow for the variations in airfoil relative thickness, wing area, aspect ratio, and taper ratio. The weight formulation is exposed next.

The final UAV weight is

$$
W_{2}=W_{1}+\Delta W_{W}+\Delta W_{H}+\Delta W_{V}
$$

or

$$
\begin{aligned}
W_{2} & =W_{1}+W_{W 1}\left(\frac{W_{W 2}}{W_{W 1}}-1\right)+W_{H 1}\left(\frac{W_{H 2}}{W_{H 1}}-1\right) \\
& +W_{V 1}\left(\frac{W_{V 2}}{W_{V 1}}-1\right)
\end{aligned}
$$

where $W_{1}$ is the initial weight of the UAV and $\Delta W_{W}, \Delta W_{H}$, and $\Delta W_{V}$ are the increments in wing, tailplane, and vertical tail weights, respectively. Indices 1 and 2 refer to initial and final conditions, respectively. Using the weight definitions of [93] for the wing, tailplane, and vertical tail, the weight increments of Eq. (6a) are given by

$$
\begin{gathered}
\Delta W_{W}=K_{W} W_{1}\left[\left(\frac{S_{2}}{S_{1}}\right)^{0.758}\left(\frac{A_{2}}{A_{1}}\right)^{0.6}\left(\frac{\lambda_{2}}{\lambda_{1}}\right)^{0.04}\left(\frac{(t / c)_{2}}{(t / c)_{1}}\right)^{-0.3}\right. \\
\left.\times\left(\frac{W_{2}}{W_{1}}\right)^{0.49}-1\right] \\
\Delta W_{H}=K_{H} W_{1}\left[\left(\frac{S_{2}}{S_{1}}\right)^{1.344}\left(\frac{A_{2}}{A_{1}}\right)^{-0.448}\left(\frac{W_{2}}{W_{1}}\right)^{0.414}-1\right] \\
\Delta W_{V}=K_{V} W_{1}\left[\left(\frac{S_{2}}{S_{1}}\right)^{1.31}\left(\frac{A_{2}}{A_{1}}\right)^{0.437}\left(\frac{W_{2}}{W_{1}}\right)^{0.49}-1\right]
\end{gathered}
$$

where $K_{W}, K_{H}$, and $K_{V}$ are the ratios of the initial component weight to the initial vehicle's total weight for the wing, tailplane, and vertical tail, respectively. For this particular UAV, their values are $K_{W}=0.15$, $K_{H}=0.03$, and $K_{V}=0.01$. Equations (7b) and (7c) were derived assuming the tailplane and the vertical tail volume coefficients remained constant during the optimization. The rest of the aircraft weight is assumed to be constant. These equations are calculated iteratively, starting with a guess value for the final weight.

The wing was optimized for the design speed of $30 \mathrm{~m} / \mathrm{s}$ with a constraint that enforces that at a speed of $15 \mathrm{~m} / \mathrm{s}$, the lift produced by the wing must be greater or equal to the weight of the aircraft. The initial airfoil for this design was the SD-2030 with a relative thickness of $8.56 \%$. This airfoil is shown in Fig. 9a. The final wing design is summarized in Tables $\underline{1}$ and $\underline{2}$, in which an increase in weight and a large reduction in wing area can be observed. The reduction in drag is achieved by reducing the wing area and airfoil thickness and by increasing airfoil camber, which mainly affects parasite drag, and by increasing aspect ratio and washout that mainly affect induced drag. The reduced chord length has a negative effect on the skin friction drag due to the resulting reduced $R e$, but it is totally offset by the more efficient wing-planform shape. The optimized airfoil can be seen in Fig. 9b.

The airfoil shape is quite different from the original airfoil. The airfoil is thinner and exhibits less maximum camber; the values being 5.79 and $2.82 \%$, respectively. Because the optimum chord, in this case, is greater than the minimum chord constraint, the wing was allowed to have taper. The resulting taper ratio was 0.66 , and the washout angle was only $0.4 \mathrm{deg}$ as seen from Table 1 .

Table 2 shows that the aircraft weight has increased $6 \%$ from the original weight. This is mainly due to the large aspect ratio and the reduced airfoil relative thickness. The parasite drag was reduced, mainly due to the area being smaller, and the induced drag was also reduced despite the increased weight. Figure 10 illustrates the drag and AOA variation, with speed for the original wing and the optimized fixed wing. The optimized wing is better than the original wing at speeds above $16 \mathrm{~m} / \mathrm{s}$. This wing, represented with the deltas in Fig. 10, has $55 \%$ less drag than the original wing at $30 \mathrm{~m} / \mathrm{s}$.

These results clearly show that different solutions are obtained when different performance constraints are imposed on the optimization problem. Even though one design can perform better than another in one flight condition, it probably will perform worse in a different flight condition. The two drag curves of Fig. 10 illustrate this very clearly. The benefits that a morphing wing can bring to aircraft design are many and very promising. By adapting its shape to the flight conditions, the wing can produce low drag over a wider speed range, thus enhancing the overall vehicle's performance. By using a morphing concept, one can design the wing, not for a design point, but for a design range.

Table 2 Drag results of the optimized fixed wing

\begin{tabular}{cccccc}
\hline \hline Wing & $W, \mathrm{~N}$ & $S, \mathrm{~m}^{2}$ & $D_{o}, \mathrm{~N}$ & $D_{i}, \mathrm{~N}$ & $D_{W}, \mathrm{~N}$ \\
\hline Original & 100.00 & 0.792 & 4.651 & 1.237 & 5.888 \\
Optimized from SD-2030 & 106.01 & 0.548 & 1.914 & 0.748 & 2.662 \\
\hline \hline
\end{tabular}

Table 3 Drag reductions from original wing design

\begin{tabular}{lrrrrr}
\hline \hline Wing & $15 \mathrm{~m} / \mathrm{s}$ & $20 \mathrm{~m} / \mathrm{s}$ & $30 \mathrm{~m} / \mathrm{s}$ & $40 \mathrm{~m} / \mathrm{s}$ & $50 \mathrm{~m} / \mathrm{s}$ \\
\hline Optimized fixed & -21.2 & 19.1 & 54.8 & 47.9 & 47.8 \\
Optimized morphing & 11.2 & 33.3 & 52.2 & 63.9 & 69.7 \\
Deformed morphing & -6.3 & 5.0 & 26.9 & 39.6 & 34.5 \\
\hline \hline
\end{tabular}

Table 4 Geometric data of the optimal morphing wing and the mechanism-deformed morphing wing

\begin{tabular}{cccc}
\hline \hline$V, \mathrm{~m} / \mathrm{s}$ & $\begin{array}{c}\text { Optimized wing } \\
\text { area, } \mathrm{m}^{2}\end{array}$ & $\begin{array}{c}\text { Deformed wing } \\
\text { area, } \mathrm{m}^{2}\end{array}$ & Area reduction, \% \\
\hline 15 & 0.902 & 0.885 & 1.88 \\
20 & 0.748 & 0.737 & 1.47 \\
30 & 0.600 & 0.583 & 2.83 \\
40 & 0.528 & 0.523 & 0.95 \\
50 & 0.528 & 0.523 & 0.95 \\
\hline \hline
\end{tabular}




\section{Morphing Wing}

Even though the tool enables a large number of design variables to be used, only 13 design variables are adopted in this design problem. The design variables are the AOA $\alpha$, the span of the wing $b$, the chord length $c$ at two semispan positions (the chord at which the wing joins the central wing and the tip chord), and the airfoil shape. In this case, the span is allowed to vary between 2.4 and $3.4 \mathrm{~m}$, and the chord length is limited to a minimum of $0.22 \mathrm{~m}$ and a maximum of $0.33 \mathrm{~m}$. The variation of the chord length between these two design chords is linear. The airfoils at the reference stations can change its thickness, and camber distribution is only limited by a thickness in the range 14 to $25.2 \mathrm{~mm}$. There is no twist of the wing because the morphing concept does not permit such mechanism, and the sweep angle at the quarter-chord position is kept constant and equal to zero. A fixed leading-edge diameter $\phi_{\mathrm{LE}}$ is also imposed. These geometric constraints are imposed due to the physical limitations of the morphing mechanisms and the rubberlike material to be used for the skin. The optimization statement is given next, in which all lengths are in meters, and speeds are in meters per second.

Minimize with regard to $v_{i}$

$$
D_{W}=D_{W}\left(v_{i}, V\right) \quad[i=1-13 \quad V \in(15,50)]
$$

subject to

$$
\begin{gathered}
L\left(v_{i}, V\right)=W \quad \phi_{\mathrm{LE}}=4.0 \times 10^{-3} \quad 2.40 \leq v_{1} \leq 3.40 \\
\quad 0.22 \leq v_{i} \leq 0.33 \quad(i=2,3) \\
4.0 \times 10^{-3} \leq\left|z_{(x / c)=0.75}\right| \leq 7.2 \times 10^{-3} \\
6.0 \times 10^{-3} \leq\left|z_{(x / c)=0.5}\right| \leq 10.8 \times 10^{-3} \\
7.0 \times 10^{-3} \leq\left|z_{(x / c)=0.25}\right| \leq 12.6 \times 10^{-3} \\
6.0 \times 10^{-3} \leq\left|z_{(x / c)=0.167}\right| \leq 10.8 \times 10^{-3} \\
5.5 \times 10^{-3} \leq\left|z_{(x / c)=0.083}\right| \leq 9.9 \times 10^{-3}
\end{gathered}
$$

where

$$
\begin{gathered}
v_{1}=b \quad v_{2}=c_{\text {root }} \quad v_{3}=c_{\text {tip }} \quad v_{4}=\alpha \\
v_{i}=(z / c)_{\text {control } j} \quad(i=5-13 \quad j=2-6,9-12)
\end{gathered}
$$

The design variables 5 to 13 are the abscissas of the airfoil's $b$ spline control point coordinates nondimensionalized by the chord length. Here, the $b$-splines are represented by 13 control points, from which the points 2 to 6 are used as design variables for the thickness distribution, and points 9 to 12 are used as design variables for the camber line of the airfoil at $0 c, 0.0833 c, 0.25 c, 0.5 c$, and $0.75 c$ (Fig. 2). In this work, only the geometry of one airfoil is changed, and all wing sections use the same surface $z$ value at the same $x / c$ position, so that all $z$ values are within the limits specified previously. The vertical length $z$ is used as a constraint, rather than the relative vertical position, because the mechanism concept places the control points at some $z$ value bound by geometric constraints irrespective of the local chord length. For example, different chord lengths have the same thickness but different relative thickness. The tool allows different airfoils to be designed at different wing stations, but due to the strict geometric constraints and the need for a simple actuation mechanism, it was decided to have identical thickness distributions at all stations. Also, it was observed that only small drag reductions were achieved with different airfoil sections across the span, which did not pay off the increased computational time required and mechanical complexity.

The initial design was the minimum wing area planform with a span of $2.4 \mathrm{~m}$ and a constant chord of $0.22 \mathrm{~m}$, set at an AOA of $0.1 \mathrm{deg}$, and a representation of the NACA 0009 airfoil (see Fig. 9a), which fits the required constraints. The wing semispan was divided into 50 sections for the lifting-line analysis. A total of 150 panels were used in the airfoil analysis, concentrating the points closer to the small radius leading edge in a cosine distribution. Convergence of the optimization proved to be very dependent on the initial design. Care must be taken when choosing the initial design and the optimization convergence parameters as referred to in Spelluci [87]. It was observed that starting the optimization at higher speeds and using the optimized design at a given speed, as the starting point for the next reduced speed, helped greatly in the optimization process. Thus, the wing was first optimized for a speed of $50 \mathrm{~m} / \mathrm{s}$. The optimum design was then used as the initial design for the next lower speed of $45 \mathrm{~m} / \mathrm{s}$. The process was then repeated for the remaining speeds. Figures 11 and 12 illustrate, respectively, the final airfoils and the geometric properties for the speeds analyzed.

In Fig. 11, the airfoils are divided into two groups: below and above $25 \mathrm{~m} / \mathrm{s}$. Above $25 \mathrm{~m} / \mathrm{s}$ (Fig. 11b), as the speed reduces from the maximum of $50 \mathrm{~m} / \mathrm{s}$, the thickness of the airfoil increases in an almost uniform manner. The same is true for camber. Above $40 \mathrm{~m} / \mathrm{s}$, the airfoil shape changes very little. Note that the lower surface shape remains almost unchanged for the geometric constraints imposed, but the upper surface rises, as the speed reduces and AOA increases, to maintain a favorable gradient pressure and delay separation. Below $25 \mathrm{~m} / \mathrm{s}$, the airfoils change quite a lot in both thickness distribution and camber distribution (Fig. 11a). As speed decreases, the chordwise location of the maximum camber moves forward to allow the flow to remain attached as long as possible to the upper surface of the thin airfoils. For example, the root airfoil relative thickness of the $14 \mathrm{~m} / \mathrm{s}$ wing is only about $6.2 \%$, due to the geometric limits. Below $16 \mathrm{~m} / \mathrm{s}$, the maximum camber position moves to about $15 \%$ of the chord. Between 16 and $25 \mathrm{~m} / \mathrm{s}$, the airfoil shape is very different from the other airfoils. Maximum camber

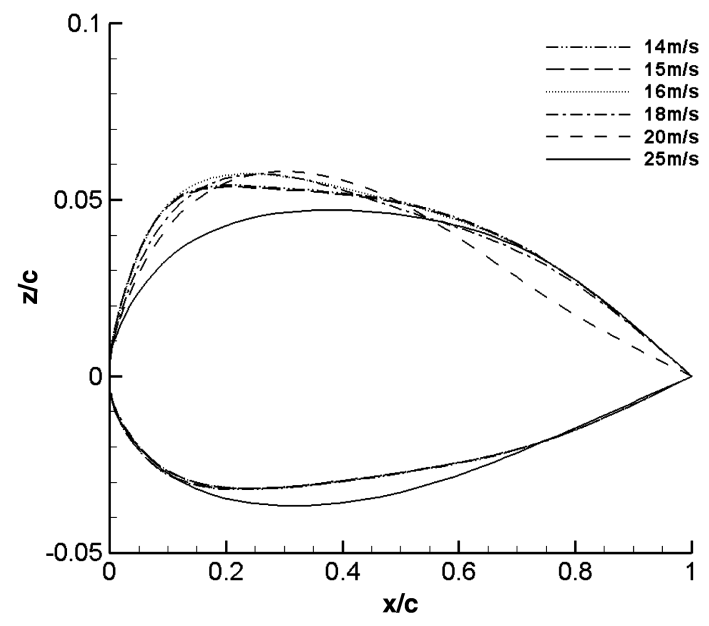

a)

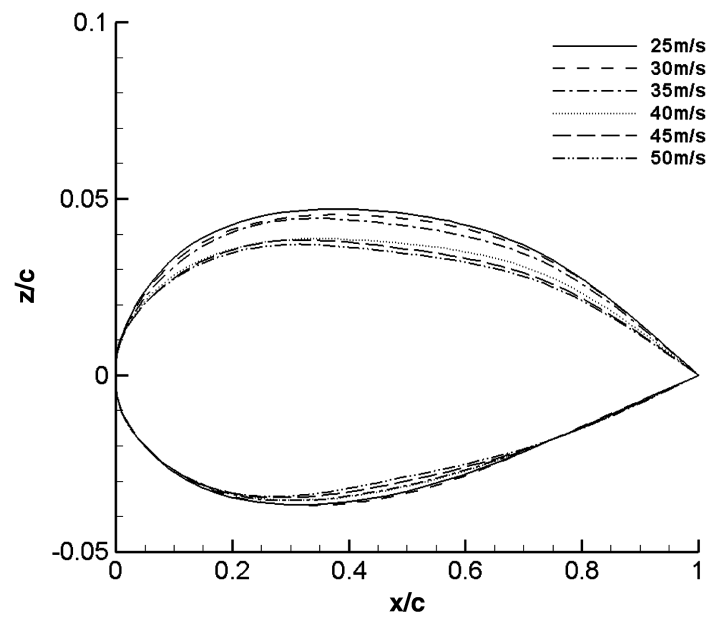

b)

Fig. 11 Morphing wing airfoils a) below $25 \mathrm{~m} / \mathrm{s}$ and b) above $25 \mathrm{~m} / \mathrm{s}$. 


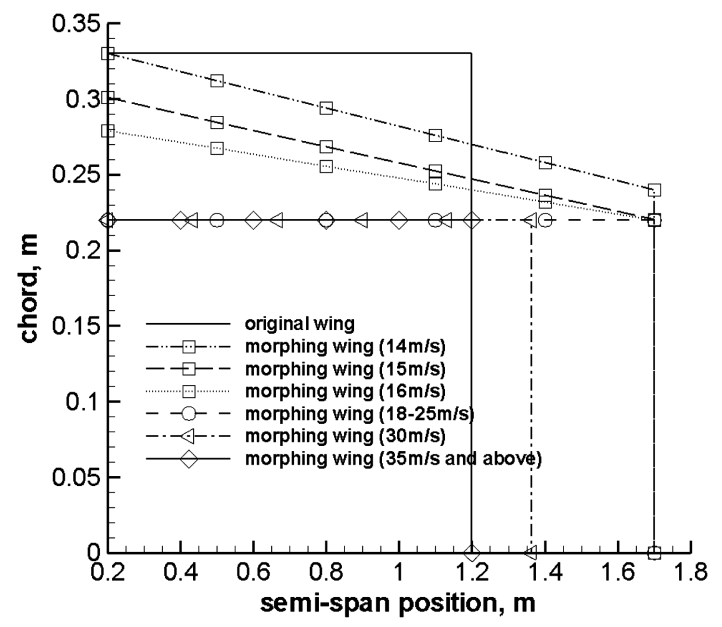

a)

Fig. 12 Morphing wing geometry: a) chord distribution and b) size and AOA.

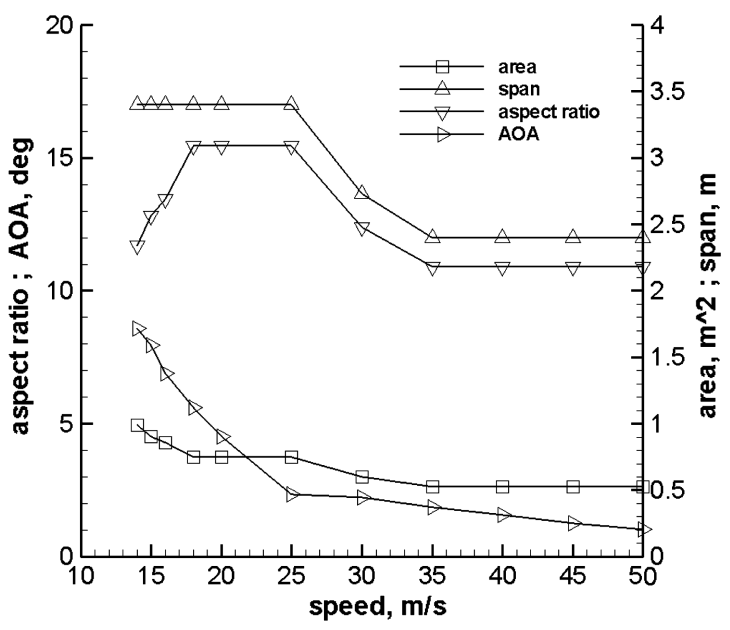

b) increases, and the camber distribution exhibits an inflection toward the trailing edge as seen from the $16 \mathrm{~m} / \mathrm{s}$ airfoil shape. This happens after the wing span reaches its maximum allowed value of $3.4 \mathrm{~m}$.

The change in planform shape is very interesting (Fig. 12a). Starting from the minimum area condition, as speed is reduced, the span progressively extends to its maximum value. Span varies from its minimum at around $35 \mathrm{~m} / \mathrm{s}$ to its maximum at about $25 \mathrm{~m} / \mathrm{s}$. The chord remains at its minimum value until $18 \mathrm{~m} / \mathrm{s}$ is reached. Only then, the chord at the root starts increasing until it reaches its upper limit. Then, the tip chord increases to achieve the required wing area. This sequence in the planform morphing of the wing is required to keep the induced drag low, which means having the highest aspect ratio possible together with the attainable taper ratio, given the constraints. It is interesting to note that the wing never reaches the maximum allowed planform area because the resulting airfoil with the chord of $0.33 \mathrm{~m}$ is very thin, and its maximum lift coefficient is much smaller than that of the resulting airfoil with the chord of $0.22 \mathrm{~m}$. It is apparent that the airfoil morphing mechanism is very restrictive as far as thickness and camber are concerned. From Fig. $12 \mathrm{~b}$, it is observed that above $25 \mathrm{~m} / \mathrm{s}$, the AOA varies very little (only $1.4 \mathrm{deg}$ ).

From these results, one expects the wing to be most efficient at $25 \mathrm{~m} / \mathrm{s}$, in which the maximum aspect ratio occurs together with the wing area just required. This can be seen from Fig. 13a, in which the morphing wing drag results are shown. In this figure, the wings are labeled with values representing the speed for which they were optimized. For instance, wing 30 is the wing geometry obtained from the optimization problem at $30 \mathrm{~m} / \mathrm{s}$. It is clearly seen that the morphing concept will adapt the wing shape for a given speed in order to keep the drag at the lowest possible value at that speed, given the morphing mechanisms geometric constraints. The morphing wing drag curve is thus given by the minimum drag values of each wing and is represented by the solid circles in Fig. 13a.

\section{Comparison of Wing Aerodynamic Designs}

In Fig. 13b, it can be seen that the drag of the morphing wing is reduced for all speeds above $15 \mathrm{~m} / \mathrm{s}$ when compared with the original wing. It is clearly seen that the morphing concept's inability to increase the camber of the wing greatly affects the wing drag at low speeds. On the other hand, its ability to reduce the wing area at higher speeds improves its performance. The drag reduction percentages at five speeds are shown in Table 3 . At cruise speed $(30 \mathrm{~m} / \mathrm{s})$, the reduction in drag is more than $5 \overline{0} \%$, an important contribution to flight efficiency. Reductions of up to $70 \%$ would be achieved at higher speeds. The optimized fixed wing is only better than the morphing wing around its design condition. Note that these values are for the wing alone. Somewhat lower gains for the complete aircraft will result, and these are analyzed later in the paper.

\section{B. Coupled Aerostructural Morphing Wing Design Results}

Figure 14 shows the deformed wings obtained from the coupled aerodynamic-structural analysis for five different airspeeds within the speed range of the UAV. Depending on the stiffness of the

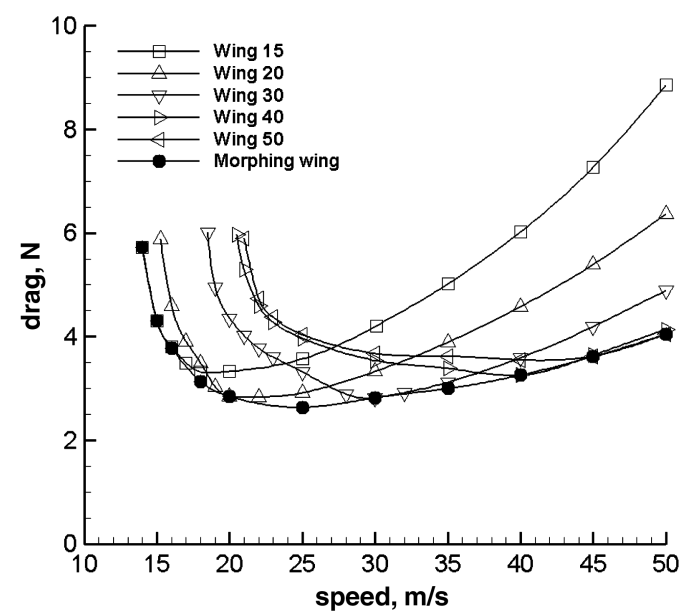

a)

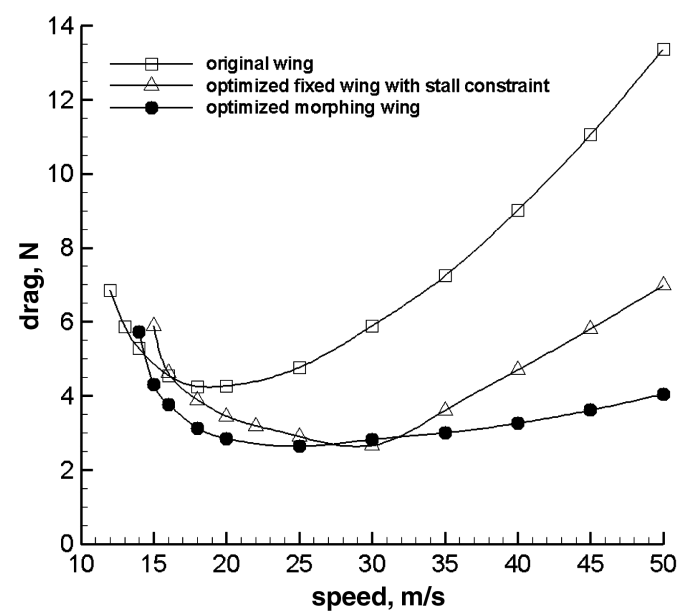

b)

Fig. 13 Morphing wing drag results: a) morphing wing and b) comparison with other wings. 
modeling strings, the skin between the ribs takes a curved or straight shape in the lines that connect control points. As the stiffness of these elements increases, the lines become straighter. This allows simulation of the expected planform area more accurately. Earlier structural models with insufficient string stiffness showed that the area reduction due to the chord reduction between the ribs was significant. This is not the case with the present structural model, as can be seen from Table 4. Other structural model improvements were made after the actuation forces were obtained from the model. Once these data are gathered, the mechanism parts were not required for the structural analysis, because only the skin had influence in the aerodynamic loading, and the mechanism parts deformation was negligible.

The parts in contact with the skin were simulated by beam elements that did not allow the skin to rotate freely at the contact points, maintaining its original angle and not behaving like a membrane in contact with the structure. Removing these beam elements, and imposing the translational displacements of the skin at the contact points, allowed the skin to behave like a membrane and contributed to achievement of an easier convergence of the aerodynamic analysis of the deformed skin, as well as a model that better represented the real case.

From the pressure coefficient plots in Fig. 15, it can be seen that, whereas the section chord length reduces as the section is farther away from the rib extension mechanism, the same (or even higher) maximum thickness of the rib section occurs due to the suction forces on the section. This will translate in a reduction of the total lift of the wing. An overall stiffer mechanism model with stiffer elastic strings would force the wing skin to deform, and increase the wing area through chord expansion along the span of the wing, but that would also mean stiffer parts for the mechanism would need to be used.
This poses a problem, due both to weight increase and geometric constraints.

Because rubber is not a rigid material, when it is wrapped as a sleeve around the wing internal mechanism and structure with some level of preextension, it tends to the shape shown in Fig. 15. Straight lines form between consecutive control points at any section that causes the reduction of the chord and thickness between consecutive ribs. As a result, the wing aerodynamic characteristics are different from the perfectly smooth optimized wing. The solution from the aerostructural analysis is shown in the deformed tip airfoils depicted in Fig. 15a. The pressure coefficient distributions around the wing (Figs. 15b, 15d, and 15f) illustrate the peaks of alternating zones of low pressure and high pressure that occur due to the small curvature of the wing surface at the control points. Wing drag was mainly affected by the section deformation. Induced drag remained almost unchanged.

Figure 16 shows the drag and AOA results. Table 5 summarizes the reduction percentages in drag, obtained by the morphing wing relative to the optimized fixed wing. The drag performance of the deformed morphing wing is not comparable to that of the optimized morphing wing, or even to that of the optimized fixed wing. The flexible skin surface deformation greatly influenced the parasite drag of this wing. The drag improvements of the optimized morphing wing over the optimized fixed wing are important except for the design speed of $30 \mathrm{~m} / \mathrm{s}$. On the other hand, the deformed morphing wing is totally outperformed by the optimized fixed wing and its stall speed increased to $15.5 \mathrm{~m} / \mathrm{s}$. The optimized morphing wing still manages a stall speed of $14 \mathrm{~m} / \mathrm{s}$.

One important advantage of the morphing wing is that the AOA between 20 and $50 \mathrm{~m} / \mathrm{s}$ varies only by $3.5 \mathrm{deg}$ for the morphing wings as opposed to the variation of $7.3 \mathrm{deg}$ for the fixed wing. This
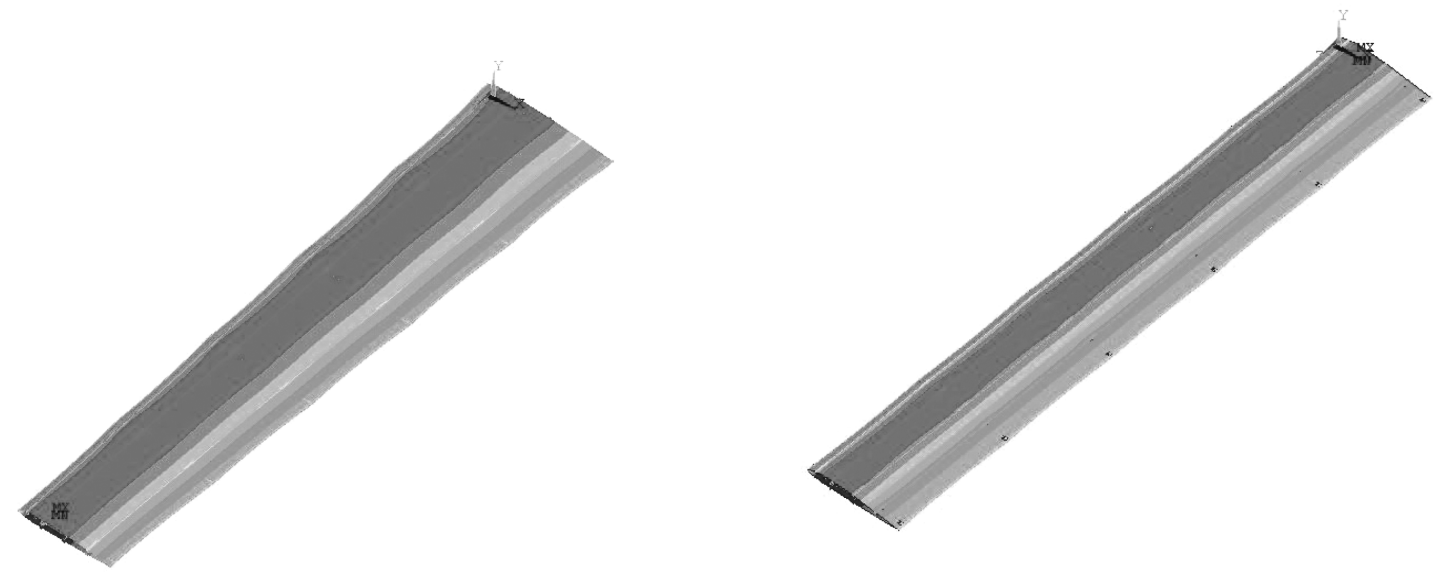

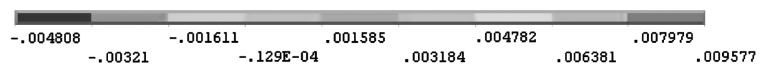

a)

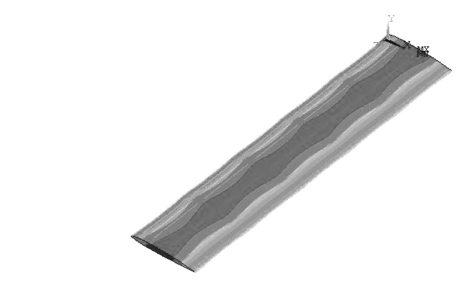

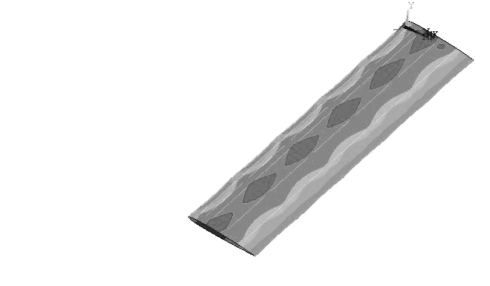

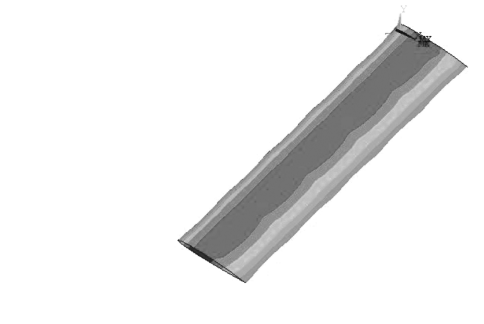

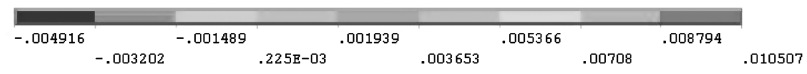

b)

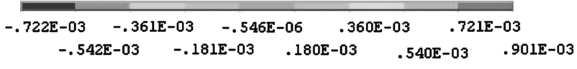

e)

Fig. 14 Vertical displacement of the skin of the deformed morphing wing at different speeds: a) $15 \mathrm{~m} / \mathrm{s}, \mathrm{b}) 20 \mathrm{~m} / \mathrm{s}, \mathrm{c}) 30 \mathrm{~m} / \mathrm{s}, \mathrm{d}) 40 \mathrm{~m} / \mathrm{s}$, and e) $50 \mathrm{~m} / \mathrm{s}$. 


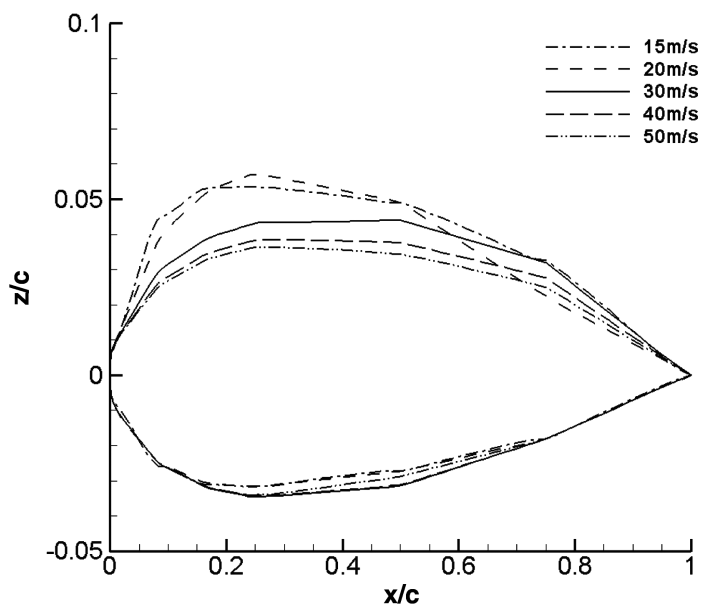

a)

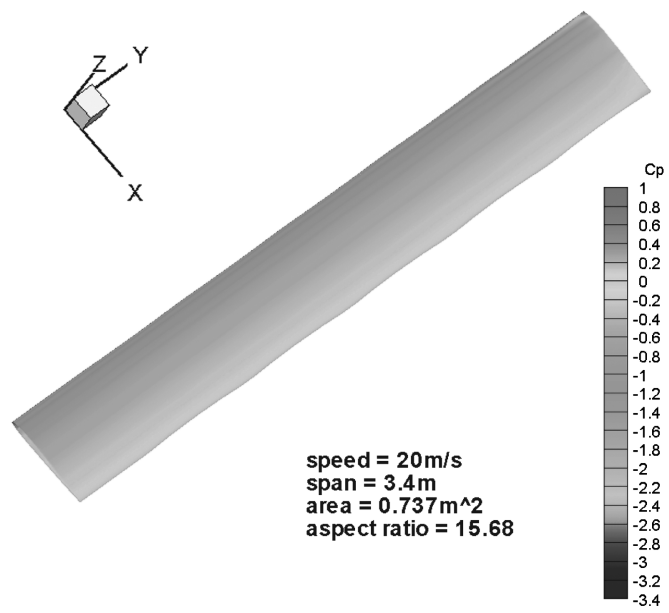

c)

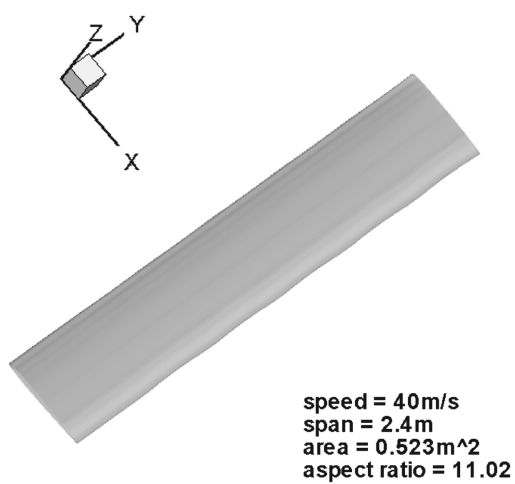

e)

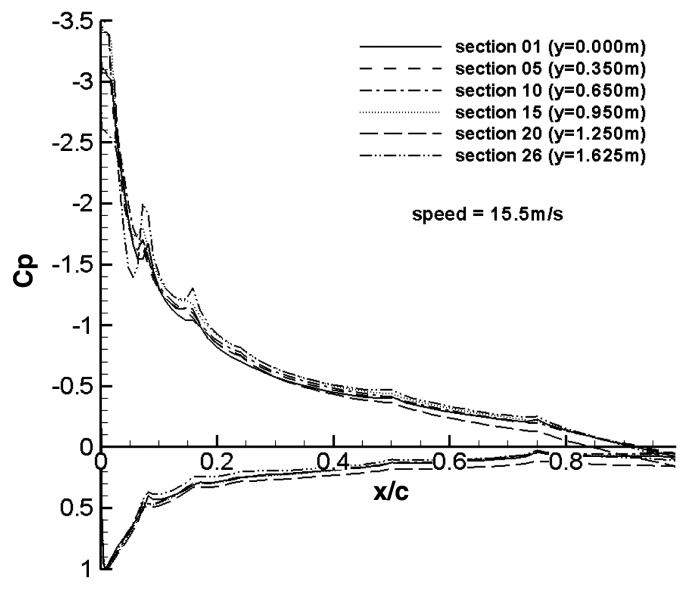

b)

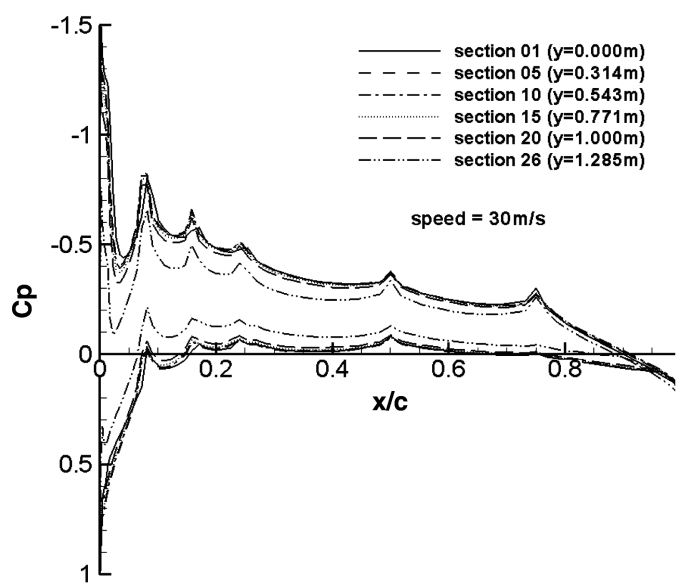

d)

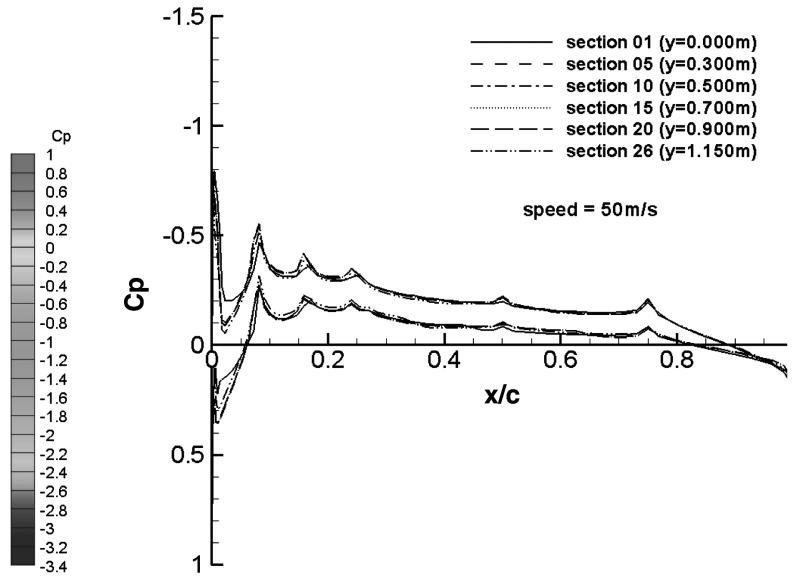

f)

Fig. 15 Deformed morphing wing results from the aerostructural analysis: a) wing sections at wing tip, b) pressure coefficient distributions at $15.5 \mathrm{~m} / \mathrm{s}$, c) wing planform at $20 \mathrm{~m} / \mathrm{s}$, d) pressure coefficient distributions at $30 \mathrm{~m} / \mathrm{s}$, e) wing planform at $40 \mathrm{~m} / \mathrm{s}$, and f) pressure coefficient distributions at $50 \mathrm{~m} / \mathrm{s}$.

situation helps in maintaining the fuselage in an almost horizontal position for most of the speed range in straight and level flight, for which some surveillance applications may be of interest. On the other hand, fuselage drag can be reduced because it may be at a small AOA to the airflow.
The assessment of these effects will be discussed in the next section. These results show that the optimal morphing wing shapes will not be achieved with the mechanism concept and flexible skin described, but the degree of approximation depends on the properties and dimensions of the mechanism components and skin material. 

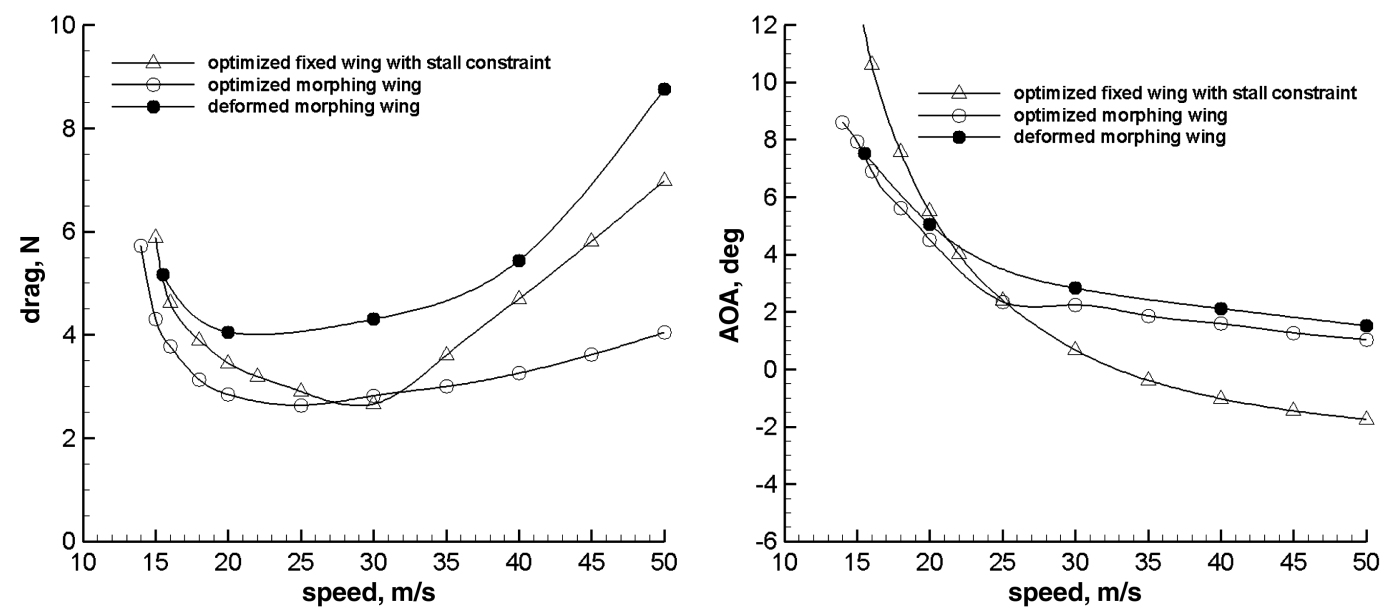

a)

b)

Fig. 16 Aerodynamic results for the morphing wing optimization problem: a) drag and b) AOA.

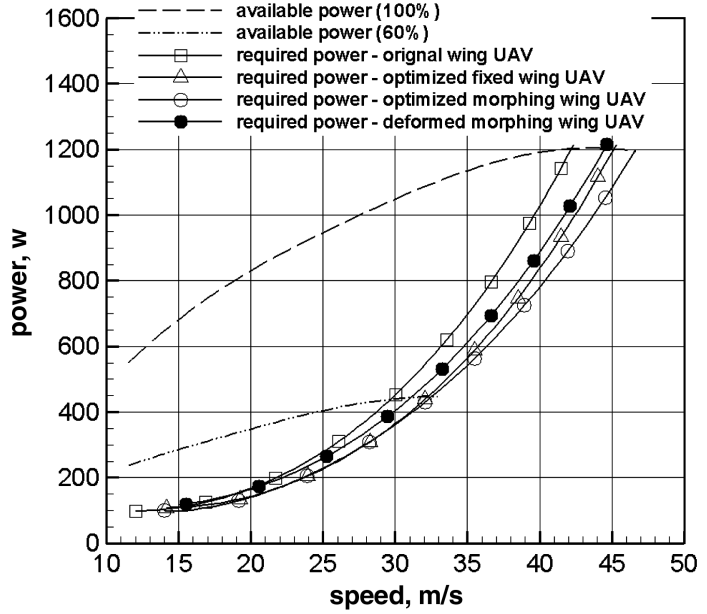

a)

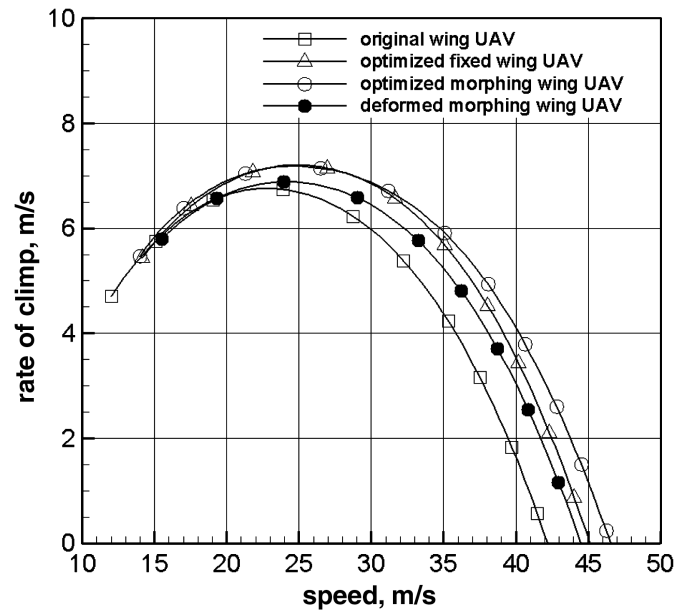

b)

Fig. 17 UAV performance with the four wings: a) required and available power with a $2.4 \mathrm{hp}$ piston engine and b) rate of climb.

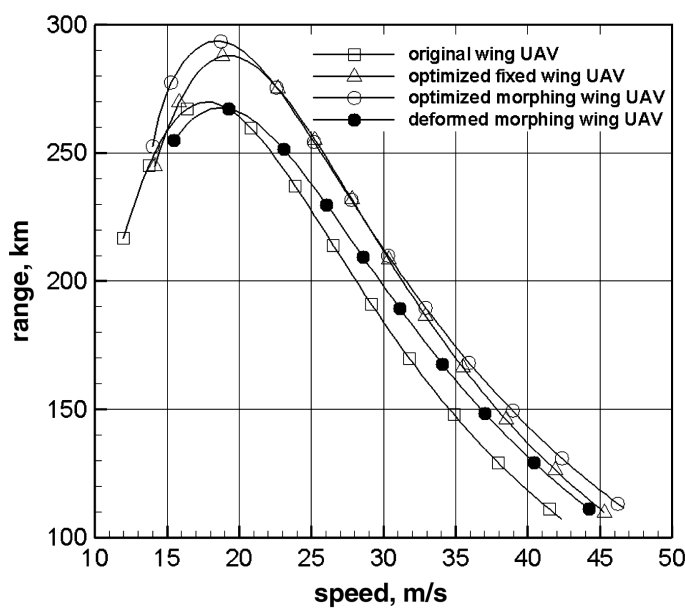

a)

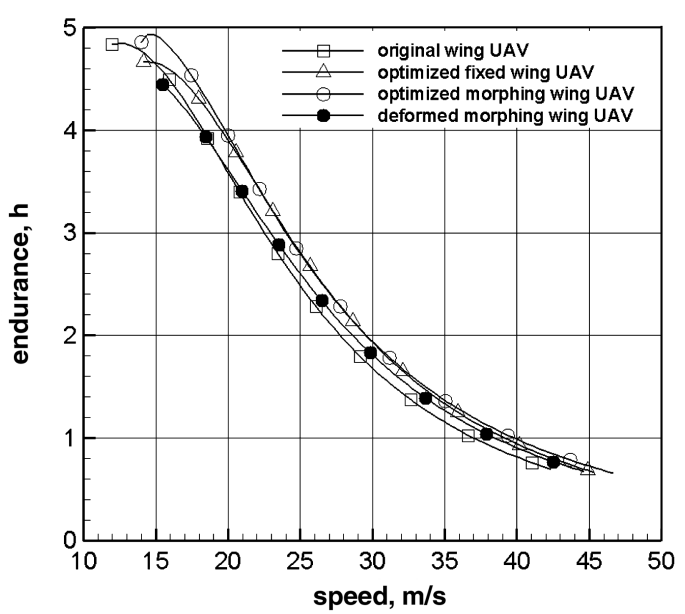

b)

Fig. 18 UAV performance with the four wings: a) range and b) endurance.

\section{UAV Performance Results}

To quantify the effect of the wing drag on the performance of the UAV, several parameters such as maximum speed, range, endurance, and rate of climb are compared with the help of Figs. 17 and 18 and Table 6 . Some comments on the relative performance between the optimized fixed wing and the morphing wings are made next.
Table 5 Drag reductions from optimized fixed wing design

\begin{tabular}{lcrrrr}
\hline \hline Wing & $15.5 \mathrm{~m} / \mathrm{s}$ & $20 \mathrm{~m} / \mathrm{s}$ & $30 \mathrm{~m} / \mathrm{s}$ & $40 \mathrm{~m} / \mathrm{s}$ & $50 \mathrm{~m} / \mathrm{s}$ \\
\hline Optimized morphing & 23.1 & 17.6 & -5.8 & 30.6 & 42.0 \\
Deformed morphing & 1.7 & -17.4 & -61.6 & -15.9 & -25.5 \\
\hline \hline
\end{tabular}


Table 6 UAV performance with the four wings

\begin{tabular}{lccccc}
\hline \hline UAV & Stall speed, $\mathrm{m} / \mathrm{s}$ & Maximum speed, $\mathrm{m} / \mathrm{s}$ & Cruise range, $\mathrm{km}$ & Cruise endurance, $\mathrm{h}$ & Max rate of climb, $\mathrm{m} / \mathrm{s}$ \\
\hline Original wing & 12.0 & 42.7 & 188 & 1.74 & 6.76 \\
Optimized fixed wing & 15.0 & 45.6 & 216 & 2.00 & 7.20 \\
Optimized morphing wing & 14.0 & 47.0 & 216 & 2.00 & 7.18 \\
Deformed morphing wing & 15.5 & 45.0 & 202 & 1.87 & 6.88 \\
\hline \hline
\end{tabular}

As far as the optimized morphing wing UAV is concerned, performance enhancements are only observed below and above $30 \mathrm{~m} / \mathrm{s}$. Maximum speed, with the $2.4 \mathrm{hp}$ engine installed, increases by $3 \%$, which is about $1.5 \mathrm{~m} / \mathrm{s}$ faster. These results predict that increased maximum range is possible to as much as $2 \%$, and the maximum endurance may increase by $5.8 \%$ for the same total UAV weight and $10 \mathrm{~N}$ of fuel. One shortcoming of the concept is the limited amount of camber achieved by the wing, resulting in an increase in the stall speed of $16.7 \%$ and reduced performance at low speeds.

As discussed previously, the deformed morphing wing is outperformed by the optimized fixed wing due to the excessive skin deformation resulting from the extending morphing mechanisms and the aerodynamic loads. In cruise, the required power of the vehicle increases by $10.4 \%$, and range and endurance are reduced by $6.5 \%$. Maximum range decreases by $7.1 \%$ and maximum endurance reduces by $3.6 \%$. These performance values are a result of the poor airfoil geometry produced by the morphing mechanism, in which the straight lines between consecutive control points favor separation as the AOA increases.

Figure 19 summarizes, in a spider plot, the performance gains that the UAV fitted with the morphing wing would achieve when compared with the optimized fixed wing. We can clearly see the improvements in takeoff distance and maximum speed that the optimized morphing wing can provide. All other performance parameters are very similar because they occur close to the design speed of the fixed wing. The deformed morphing wing exhibits performance values that are all below the fixed wing.

\section{Conclusions}

Although this work is not complete, some conclusions can be drawn. The aerodynamic optimization carried out reveals that reductions in wing drag of up to $30 \%$ and more can be obtained by morphing the wing with the concept presented, representing important performance improvements in offdesign conditions. However, the results also show that, for the actual deformed morphing wing, no gains are possible due mainly to the flexible skin. Improvements in the results can be achieved if, at the rib sections,

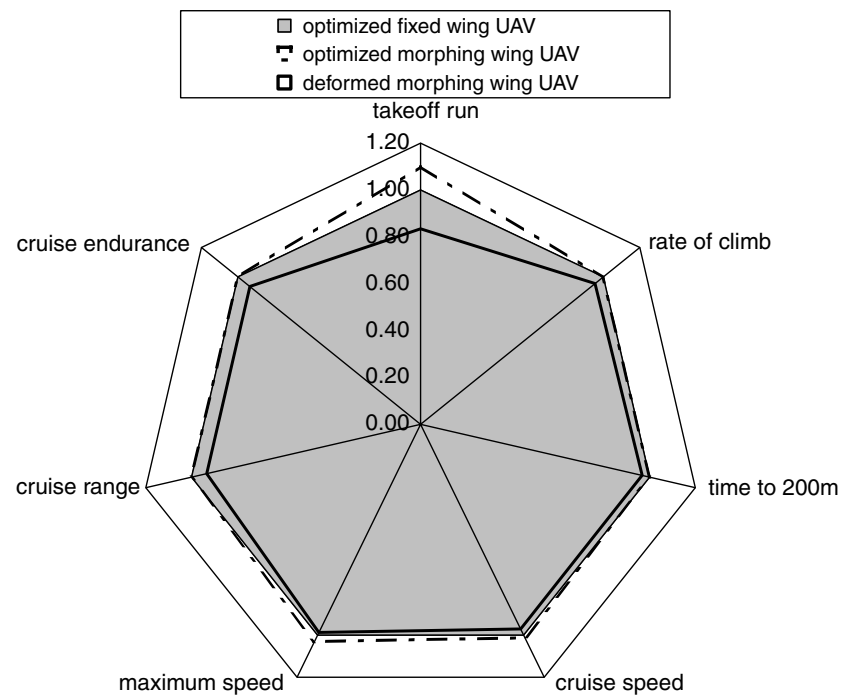

Fig. 19 Performance improvements. some conformal elements are added to prevent the surface from forming straight lines between the control points and/or more control points are used, which would result in a better approximation to the desired shape. Further work is being done on this subject.

A multidisciplinary design optimization tool, containing aerodynamic, structural analyses, and weight prediction information was developed to help design a morphing wing for an experimental UAV in order to improve and quantify its performance. However, a better feedback of the structural weight into the aerodynamic optimization step, as well as a better representation of the airfoil achieved by the morphing mechanism, should be used to turn the tool into a more robust one.

The preliminary experimental studies performed so far give a better understanding of the complexity involved in using a flexible skin material. Traditional aerodynamic relationships do not apply directly, and one must still demonstrate whether the flexible skin material adopted can be used to obtain drag reductions for performance improvement.

This paper shows the methodology and numerical results obtained by the authors in the context of a larger work with the objective to design, build, and test a morphing wing. As in any engineering project, the design is an iterative process, therefore some of the assumptions made may not translate into viable structures and the mechanisms shown may suffer considerable changes. The studies will continue in order to explore different skin materials and morphing benefit/weight increase relationships. Future work stages will include computational studies with different experimental skin material data, experimental determination of force and moment requirements for the morphing mechanism, and further and more indepth wind-tunnel testing of the morphing wing at different flight speeds.

\section{References}

[1] Sanders, B., Eastep, F. E., and Forster, E., "Aerodynamic and Aeroelastic Characteristics of Wings with Conformal Control Surfaces for Morphing Aircraft," Journal of Aircraft, Vol. 40, No. 1, Jan.Feb. 2003, pp. 94-99. doi: $10.2514 / 2.3062$

[2] Johnston, C. O., Mason, W. H., Han, C., Robertshaw, H. H., and Inman, D. J., "Actuator-Work Concepts Applied to Unconventional Aerodynamic Control Devices," 10th AIAA/ISSMO Multidisciplinary Analysis and Optimization Conference, AIAA, Paper 2004-4366, 30 Aug.-1 Sept. 2004.

[3] Gern, F. H., Inman, D. J., and Kapania, R. K., "Structural and Aeroelastic Modeling of General Planform Wings with Morphing Airfoils," AIAA Journal, Vol. 40, No. 4, Apr. 2002, pp. 628-637. doi: $10.2514 / 2.1719$

[4] Gern, F. H., Inman, D. J., and Kapania, R. K., "Computation of Actuation Power Requirements for Smart Wings with Morphing Airfoils," AIAA Journal, Vol. 43, No. 12, Dec. 2005, pp. 2481-2486. doi: $10.2514 / 1.20367$

[5] Ricci, S., and Terraneo, M., "Conceptual Design of an Adaptive Wing for a Three-Surfaces Airplane," 46th AIAA/ASME/ASCE/AHS/ASC Structures, Structural Dynamics, and Materials Conference, AIAA, Paper 2005-1959, 18-21 Apr. 2005.

[6] Monner, H. P., "Realization of an Optimized Wing Camber by Using Formvariable Flap Structures," Aerospace Science and Technology, Vol. 5, No. 7, 2001, pp. 445-455. doi:10.1016/S1270-9638(01)01118-X

[7] Diaconu, C. G., Weaver, P. M., and Mattioni, F., "Solutions for Morphing Airfoil Sections Using Bi-stable Laminated Composite Structures," 48th AIAA/ASME/ASCE/AHS/ASC Structures, Structural Dynamics, and Materials Conference, AIAA, Paper 2007-1719, 23-26 Apr. 2007. 
[8] Vos, R., Breuker, R. D., and Tiso, P., "Morphing Wing Flight Control via Postbuckled Precompressed Piezoelectric Actuators," Journal of Aircraft, Vol. 44, No. 4, July-Aug. 2007, pp. 1060-1068. doi:10.2514/1.21292

[9] Cadogan, D., Smith, T., Uhelsky, F., and MacKusick, M., "Morphing Inflatable Wing Development for Compact Package Unmanned Aerial Vehicles," 45th AIAA/ASME/ASCE/AHS/ASC Structures, Structural Dynamics, and Materials Conference, AIAA, Paper 2004-1807, 19 22 Apr. 2004.

[10] Simpson, A., Coulombe, N., Jacob, J., and Smith, S., "Morphing of Inflatable Wings," 46th AIAA/ASME/ASCE/AHS/ASC Structures, Structural Dynamics, and Materials Conference, AIAA, Paper 20052110, 18-21 Apr. 2005.

[11] Bae J.-S., Seigler, T. M., and Inman, D. J., "Aerodynamic and Static Aeroelastic Characteristics of a Variable-Span Morphing Wing," Journal of Aircraft, Vol. 42, No. 2, Mar.-Apr. 2005, pp. 528-534. doi:10.2514/1.4397

[12] Blondeau, J. E., and Pines, D. J., "Pneumatic Morphing Aspect Ratio Wing," 45th AIAA/ASME/ASCE/AHS/ASC Structures, Structural Dynamics, and Materials Conference, AIAA, Paper 2004-1808, 1922 Apr. 2004.

[13] Blondeau, J. E., and Pines, D. J., "Design and Testing of a Pneumatic Telescopic Wing for Unmanned Aerial Vehicles," Journal of Aircraft, Vol. 44, No. 4, July-Aug. 2007, pp. 1088-1099. doi: $10.2514 / 1.22205$

[14] Manzo, J. E., "Analysis and Design of a Hyper-Elliptical Cambered Span Morphing Aircraft Wing," M.S. Thesis, Cornell Univ., Ithaca, NY, Aug. 2006.

[15] Ramrkahyani, D. S., Lesieutre, G. A., Frecker, M., and Bharti, S., "Aircraft Structural Morphing Using Tendon-Actuated Compliant Cellular Trusses," Journal of Aircraft, Vol. 42, No. 6, Nov.-Dec. 2005, pp. 1614-1620. doi: $10.2514 / 1.9984$

[16] Stubbs, M. D., "Kinematic Design and Analysis of a Morphing Wing," M.S. Thesis, Mechanical Engineering, Virginia Polytechnic Inst. and State Univ., Blacksburg, VA, Dec. 2003.

[17] Abdulrahim, M., and Lind, R., "Flight Testing and Response Characteristics of a Variable Gull-Wing Morphing Aircraft," Guidance, Navigation, and Control Conference and Exhibit, AIAA Paper 20045113, 16-19 Aug. 2004

[18] Abdulrahim, M., Garcia, H., Ivey, G. F., and Lind, R., "Flight Testing a Micro Air Vehicle Using Morphing for Aeroservoelastic Control," 45th AIAA/ASME/ASCE/AHS/ASC Structures, Structural Dynamics, and Materials Conference, AIAA, Paper 2004-1674, 19-22 Apr. 2004.

[19] Abdulrahim, M., Garcia, H., and Lind, R., "Flight Characteristics of Shaping the Membrane Wing of a Micro Air Vehicle," Journal of Aircraft, Vol. 42, No. 1, Jan.-Feb. 2005, pp. 131-137. doi: $10.2514 / 1.4782$

[20] Stanford, B., Abdulrahim, M., Lind, R., and Ifju, P., "Investigation of Membrane Actuation for Roll Control of a Micro Air Vehicle," Journal of Aircraft, Vol. 44, No. 3, May-June 2007, pp. 741-749. doi:10.2514/1.25356

[21] Bourdin, P., Gatto, A., and Friswell, M. I., "Aircraft Control via Variable Cant-Angle Winglets," Journal of Aircraft, Vol. 45, No. 2, Mar.Apr. 2008, pp. 414-423. doi: $10.2514 / 1.27720$

[22] Shelton, A., Tomar, A., Prasad, J. V. R., Smith, M. J., and Komerath, N., "Active Multiple Winglets for Improved Unmanned-Aerial-Vehicle Performance," Journal of Aircraft, Vol. 43, No. 1, Jan.-Feb. 2006, pp. $110-116$ doi: $10.2514 / 1.13987$

[23] Lee, D. H., and Weisshaar, T. A., "Aeroelastic Studies on a Folding Wing Configuration," 46th AIAA/ASME/ASCE/AHS/ASC Structures, Structural Dynamics, and Materials Conference, AIAA, Paper 20051996, 18-21 Apr. 2005.

[24] Snyder, M. P., Sanders, B., Estep, F. E., and Frank, G. J., "Vibration and Flutter Characteristics of a Folding Wing," 46th AIAA/ASME/ASCE/ AHS/ASC Structures, Structural Dynamics, and Materials Conference, AIAA, Paper 2005-1994, 18-21 Apr. 2005.

[25] Bye, D. R., and McClure, P. D., "Design of a Morphing Vehicle," 48th AIAA/ASME/ASCE/AHS/ASC Structures, Structural Dynamics, and Materials Conference, AIAA, Paper 2007-1728, 23-26 Apr. 2007.

[26] Love, M. H., Zink, P. S., Stroud, R. L., Bye D. R, Rizk, S., and White, D., "Demonstration of Morphing Technology through Ground and Wind Tunnel Tests," 48th AIAA/ASME/ASCE/AHS/ASC Structures, Structural Dynamics, and Materials Conference, AIAA, Paper 20071729, 23-26 Apr. 2007.

[27] Ivanco, T. G., Scott, R. C., Love, M. H., and Zink, P. S., "Validation of the Lockheed Martin Morphing Concept with Wind Tunnel Testing," 48th AIAA/ASME/ASCE/AHS/ASC Structures, Structural Dynamics, and Materials Conference, AIAA, Paper 2007-2235, 23-26 Apr. 2007.

[28] Flanaganl, J. S., Strutzenberg, R. C., Myers, R. B., and Rodrian, J. E., "Development and Flight Testing of a Morphing Aircraft, the NextGen MFX-1," 48th AIAA/ASME/ASCE/AHS/ASC Structures, Structural Dynamics, and Materials Conference, AIAA, Paper 2007-1707, 23 26 Apr. 2007.

[29] Andersen, G. R., Cowan, D. L., and Piatak, D. J., "Aeroelastic Modeling, Analysis and Testing of a Morphing Wing Structure," 48th AIAA/ASME/ASCE/AHS/ASC Structures, Structural Dynamics, and Materials Conference, AIAA, Paper 2007-1734, 23-26 Apr. 2007.

[30] Gandhi, N., Jha, A., Monaco, J., Seigler, T. M., Ward, D., and Inman, D. J., "Intelligent Control of a Morphing Aircraft," 48th AIAA/ASME/ ASCE/AHS/ASC Structures, Structural Dynamics, and Materials Conference, AIAA, Paper 2007-1716, 23-26 Apr. 2007.

[31] Neal, D. A., III, "Design, Development, and Analysis of a Morphing Aircraft Model for Wind Tunnel Experimentation," M.S. Thesis, Virginia Polytechnic Inst. and State Univ., Blacksburg, VA, Apr. 2006.

[32] Perkins, D. A., Reed, J. L., Jr., and Havens, E., "Morphing Wing Structures for Loitering Air Vehicles," 45th AIAA/ASME/ASCE/AHS/ ASC Structures, Structural Dynamics, and Materials Conference, AIAA, Paper 2004-1888, 19-22 Apr. 2004

[33] Moniz, P. A. A., "Adaptive Aeroelastic Aircraft Structures," Ph.D Thesis, Univ. Técnica de Lisboa, Lisbon, 2005.

[34] Thill, C., Etches, J., Bond, I., Potter, K., and Weaver, P., "Morphing Skins," Aeronautical Journal, Vol. 112, No. 1129, Mar. 2008, pp. 117139.

[35] Tobushi, H., Hara, H., Yamada, E., and Hayashi, S., "Thermomechanical Properties in a Thin Film of Shape Memory Polymer of Polyurethane Series," Smart Materials and Structures, No. 4, No. 5, 1996, pp. 483-491. doi:10.1088/0964-1726/5/4/012

[36] Perkins, D. A., Reed, J. L. Jr., and Havens, E., "Morphing Wing Structures for Loitering Air Vehicles," 45th AIAA/ASME/ASCE/AHS/ ASC Structures, Structural Dynamics, and Materials Conference, AIAA, Paper 2004-1888, 19-22 Apr. 2004.

[37] Bilgen, O., Kochersberger, K., Diggs, E. C., Kurdila, A. J., and Inman, D. J., "Morphing Wing Micro-Air-Vehicle via Macro-Fiber-Composite Actuators," 48th AIAA/ASME/ASCE/AHS/ASC Structures, Structural Dynamics, and Materials Conference, AIAA, Paper 2007-1785, 23-26 Apr. 2007.

[38] Murray, G., Gandhi, F., and Bakis, C., "Flexible Matrix Composite Skins for One-Dimensional Wing Morphing," 48th AIAA/ASME/ ASCE/AHS/ASC Structures, Structural Dynamics, and Materials Conference, AIAA, Paper 2007-1737, 23-26 Apr. 2007.

[39] Reich, G. W., Sanders, B., and Joo, J. J., "Development of Skins for Morphing Aircraft Applications via Topology Optimization," 48th AIAA/ASME/ASCE/AHS/ASC Structures, Structural Dynamics, and Materials Conference, AIAA, Paper 2007-1738, 23-26 Apr. 2007.

[40] Hicks, R., and Henne, P., "Wing Design by Numerical Optimization," Journal of Aircraft, Vol. 15, No. 7, July 1978, pp. 407-413. doi: $10.2514 / 3.58379$

[41] Huyse, L., Padula, S., Lewis, R., and Li, W., "Probabilistic Approach to Free-Form Airfoil Shape Optimization Under Uncertainty," AIAA Journal, Vol. 40, No. 9, Sept. 2002, pp. 1764-1772. doi: $10.2514 / 2.1881$

[42] Lee, S. W., and Kwon, O. J., "Robust Airfoil Shape Optimization Using Design for Six Sigma," Journal of Aircraft, Vol. 43, No. 3, MayJune 2006, pp. 843-846. doi: $10.2514 / 1.17359$

[43] Winnemoller, T., and van Dam, C. P., "Design and Numerical Optimization of Thick Airfoils Including Blunt Trailing Edges," Journal of Aircraft, Vol. 44, No. 1, Jan.-Feb. 2007, pp. 232-240. doi: $10.2514 / 1.23057$

[44] Wauquiez, C., "Shape Optimization of Low Speed Airfoils Using MATLAB and Automatic Differentiation," Lic. Thesis, Dept. of Numerical Analysis and Computing Science, Royal Inst. of Technology, Stockholm, 2000.

[45] Namgoong, H., Crossley, W. A., and Lyrintzis, A. S., "Global Optimization Issues for Transonic Airfoil Design," 9th AIAA/ISSMO Multidisciplinary Analysis and Optimization Conference, AIAA Paper 2002-5641, 4-6 Sept. 2002.

[46] Padula, S. L., and Li, W., "Options for Robust Airfoil Optimization Under Uncertainty," 9th AIAA/ISSMO Multidisciplinary Analysis and Optimization Conference, AIAA Paper 2002-5602, 4-6 Sept. 2002.

[47] Nemec, M., Zingg, D. W., and Pulliam, T, H., "Multi-Point and MultiObjective Aerodynamic Shape Optimization," 9th AIAA/ISSMO Multidisciplinary Analysis and Optimization Conference, AIAA Paper 2002-5548, 4-6 Sept. 2002. 
[48] Secanell, M., and Suleman, A., "Sequential Optimization Algorithms for Aerodynamic Shape Optimization," 10th AIAA/ISSMO Symposium on Multidisciplinary Analysis and Optimization, AIAA Paper 2004-4631, 30 Aug.-1 Sept. 2004.

[49] Secanell, M., and Suleman, A., "Numerical Evaluation of Optimization Algorithms for Low Reynolds Number Aerodynamic Shape Optimization," AIAA Journal, Vol. 43, No. 10, Oct. 2005, pp. 22622267 doi:10.2514/1.12563

[50] Nemec, M., and Zigg, D., "Multi-Point and Multi-Objective Aerodynamic Shape Optimization," 9th AIAA/ISSMO Symposium on Multidisciplinary Analysis and Optimization, AIAA Paper 20025548, 4-6 Sept. 2002.

[51] Peigin, S., and Epstein, B., "Multipoint Aerodynamic Design of WingBody Configurations for Minimum Drag," Journal of Aircraft, Vol. 44, No. 3, May-June 2007, pp. 971-980. doi: $10.2514 / 1.26746$

[52] Reuther, J., Alonso, J., Jameson, A., Eimlinger, M., and Saunders, D., "Constrained Multipoint Aerodynamic Shape Optimization Using an Adjoint Formulation and Parallel Computers: Part 1," Journal of Aircraft, Vol. 36, No. 1, 1999, pp. 51-60. doi: $10.2514 / 2.2413$

[53] Reuther, J., Alonso, J., Jameson, A., Eimlinger, M., and Saunders, D., "Constrained Multipoint Aerodynamic Shape Optimization Using an Adjoint Formulation and Parallel Computers: Part 2," Journal of Aircraft, Vol. 36, No. 1, 1999, pp. 61-74. doi: $10.2514 / 2.2414$

[54] Nadarajah, S. K., Jameson, A., and Alonso, J. J., "Sonic Boom Reduction Using an Adjoint Method for Wing-Body Configurations in Supersonic Flow," 9th AIAA/ISSMO Multidisciplinary Analysis and Optimization Conference, AIAA Paper 2002-5547, 4-6 Sept. 2002.

[55] Martins, J. R. R. A., "A Coupled-Adjoint Method for High-Fidelity Aero-Structural Optimization," Ph.D. Dissertation, Stanford Univ., Stanford, CA, Nov. 2002.

[56] Martins, J. R. R. A., Alonso, J. J., and Reuther, J. J., "Complete Configuration Aero-Structural Optimization Using a Coupled Sensitivity Analysis Method," 9th AIAA/ISSMO Multidisciplinary Analysis and Optimization Conference, AIAA Paper 2002-5402, 46 Sept. 2002

[57] Martins, J. R. R. A., Alonso, J. J., and Reuther, J. J., “A Coupled-Adjoint Sensitivity Analysis Method for High-Fidelity Aero-Structural Design," Optimization and Engineering, Springer Science, Vol. 6, No. 1, Mar. 2005, pp. 33-62. doi:10.1023/B:OPTE.0000048536.47956.62

[58] Piperni, P., Abdo, M., and Kafyeke, F., "The Application of MultiDisciplinary Optimization Technologies to the Design of a Business Jet," 10th AIAA/ISSMO Multidisciplinary Analysis and Optimization Conference, AAIA Paper 2004-4370, 30 Aug.-1 Sept. 2004.

[59] Laban, M., and Herrmann, U., "Multi-Disciplinary Analysis and Optimization Applied to Supersonic Aircraft," 48th AIAA/ASME/ ASCE/AHS/ASC Structures, Structural Dynamics, and Materials Conference, AIAA Paper 2007-1857, 23-26 Apr. 2007.

[60] Shi, G., Renaud, G., Yang, X., Zhang, F., and Chen, S., "Integrated Wing Design with Three Disciplines," 9th AIAA/ISSMO Multidisciplinary Analysis and Optimization Conference, AIAA Paper 20025405, 4-6 Sept. 2002.

[61] Walsh, J. L., Stroud, W. J., Dunn, H. J., Barthelemey, J.-F., and Weston, R. P., "Minimum Weight Structural Design of Three Alternate HSCT Concepts," 9th AIAA/ISSMO Multidisciplinary Analysis and Optimization Conference, AIAA Paper 2002-5407, 4-6 Sept. 2002.

[62] Limmek, T., Kießling, F., and Hönlinger, H., "Multidisciplinary Wing Optimization using a Wing Box Layout Concept and a Parametric Thickness Model," 9th AIAA/ISSMO Multidisciplinary Analysis and Optimization Conference, AIAA Paper 2002-5657, 4-6 Sept. 2002.

[63] Vankan, W. J., and Laban, M., "A SPINEware Based Computational Design Engine for Integrated Multi-Disciplinary Aircraft Design," 9th AIAA/ISSMO Multidisciplinary Analysis and Optimization Conference, AIAA Paper 2002-5445, 4-6 Sept. 2002.

[64] Laban, M., Arendsen, P., Rouwhorst, W. F. J. A., and Vakan, W. J., “A Computational Design Engine for Multi-Disciplinary Optimisation with Application to a Blended Wing Body Configuration," 9th AIAA/ ISSMO Multidisciplinary Analysis and Optimization Conference, AIAA Paper 2002-5446, 4-6 Sept. 2002.

[65] La Rocca, G., Krakers, L., and van Tooren, M. J. L., "Development of an ICAD Generative Model for Blended Wing Body Aircraft Design," 9th AIAA/ISSMO Multidisciplinary Analysis and Optimization Conference, AIAA Paper 2002-5447, 4-6 Sept. 2002.

[66] Qin, N., Vavalle, A., Le Moigne, A., Laban, M., Hackett, K., and Weinerfelt, P., "Aerodynamic Studies for Blended Wing Body Aircraft," 9th AIAA/ISSMO Multidisciplinary Analysis and Optimization Conference, AIAA Paper 2002-5448, 4-6 Sept. 2002.

[67] Gilmore, R., Wakayama, S., and Roman, D., "Optimization of HighSubsonic Blended-Wing-Body Configurations," 9th AIAA/ISSMO Multidisciplinary Analysis and Optimization Conference, AIAA Paper 2002-5666, 4-6 Sept. 2002.

[68] Willcox, K., and Wakayama, S., "Simultaneous Optimization of a Multiple-Aircraft Family," Journal of Aircraft, Vol. 40, No. 4, JulyAug. 2003, pp. 616-622.

doi: $10.2514 / 2.3156$

[69] Secanell, M., Suleman, A., and Gamboa, P., "Design of a Morphing Airfoil Using Aerodynamic Shape Optimization," AIAA Journal, Vol. 44, No. 7, July 2006, pp. 1550-1562. doi: $10.2514 / 1.18109$

[70] Gano, S. E., and Renaud, J. E., "Optimized Unmanned Aerial Vehicle with Wing Morphing for Extended Range and Endurance," 9th AIAA/ ISSMO Multidisciplinary Analysis and Optimization Conference, AIAA Paper 2002-5668, 4-6 Sept. 2002.

[71] Santhanakrishnan, A., Pern, N. J., and Jacob, J. D., "Optimization and Validation of a Variable Camber Airfoil," 46th AIAA/ASME/ASCE/ AHS/ASC Structures, Structural Dynamics, and Materials Conference, AIAA Paper 2005-1956, 18-21 Apr. 2005.

[72] Natarajan, A., Kapania, R. K., and Inman, D. J., "Aeroelastic Optimization of Adaptive Bumps for Yaw Control," Journal of Aircraft, Vol. 41, No. 1, Jan.-Feb. 2004, pp. 175-185. doi:10.2514/1.477

[73] Gano, S. E., Pérez, V. M., Renaud, J. E., Batill, S. M., and Sanders, B., "Multilevel Variable Fidelity Optimization of a Morphing Unmanned Aerial Vehicle," 45th AIAA/ASME/ASCE/AHS/ASC Structures, Structural Dynamics, and Materials Conference, AIAA Paper 20041763, 19-22 Apr. 2004.

[74] Rusnell, M. T., Gano, S. E., Pérez, V. M., Renaud, J. E., and Batill, S M., "Morphing UAV Pareto Curve Shift for Enhanced Performance," 45th AIAA/ASME/ASCE/AHS/ASC Structures, Structural Dynamics, and Materials Conference, AIAA, Paper 2004-1682, 19-22 Apr. 2004.

[75] Namgoong, H., Crossley, W. A., and Lyrintzis, A. S., "Aerodynamic Optimization of a Morphing Airfoil Using Energy as an Objective," AIAA Journal, Vol. 45, No. 9, Sept. 2007, pp. 2113-2124. doi: $10.2514 / 1.24355$

[76] Maute, K., and Reich, G. W., "Integrated Multidisciplinary Topology Optimization Approach to Adaptive Wing Design," Journal of Aircraft, Vol. 43, No. 1, Jan.-Feb. 2006, pp. 253-263. doi: $10.2514 / 1.12802$

[77] Skillen, M. D., and Crossley, W. A., "Developing Response Surface Based Wing Weight Equations for Conceptual Morphing Aircraft Sizing," 46th AIAA/ASME/ASCE/AHS/ASC Structures, Structural Dynamics, and Materials Conference, AIAA Paper 2005-1960, 18 21 Apr. 2005.

[78] Skillen, M. D., and Crossley, W. A., "Modeling and Optimization for Morphing Wing Concept Generation," NASA CR 2007-214860, Mar. 2007

[79] Skillen, M. D., and Crossley, W. A., "Morphing Wing Weight Predictors and Their Application in a Template-Based Morphing Aircraft Sizing Environment II," NASA CR 2008-214903, Feb. 2008.

[80] Skillen, M. D., and Crossley, W. A., "Implementation of Structural Sizing Strategies for Morphing Wing Structures Using Common Toolsets," 49th AIAA/ASME/ASCE/AHS/ASC Structures, Structural Dynamics, and Materials Conference, Paper 2008-2048, 710 Apr. 2008.

[81] Love, M., Zink, P., Stroud, R., Bye, D., and Chase, C., "Impact of Actuation Concepts on Morphing Aircraft Structures," 45th AIAA/ ASME/ASCE/AHS/ASC Structures, Structural Dynamics, and Materials Conference, AIAA Paper 2004-1724, 19-22 Apr. 2004.

[82] Samareh, J. A., Chwalowski, P., Horta, L. G., Piatak, D. J., and McGowan, A.-M. R., "Integrated Aerodynamic/Structural/Dynamic Analyses of Aircraft with Large Shape Changes," 48th AIAA/ASME/ ASCE/AHS/ASC Structures, Structural Dynamics, and Materials Conference, AIAA Paper 2007-2346, 23-26 Apr. 2007.

[83] Cesnik, C. E. S., Lat, H. R., and Martin, C. A., "A Framework for Morphing Capability Assessment," 45th AIAA/ASME/ASCE/AHS/ ASC Structures, Structural Dynamics, and Materials Conference, AIAA Paper 2004-1654, 19-22 Apr. 2004.

[84] Drela, M., and Youngren, H., XFOIL 6.94 User Guide, published by the authors, Cambridge, MA, 10 Dec. 2001.

[85] Gamboa, P. V., Multidisciplinary Design Optimization of Morphing Aircraft, Ph.D. Thesis, Univ. da Beira Interior, Covilhã, Portugal, Oct. 2007.

[86] Anderson, J. D., Corda, S., and Wie, D. M. V., "Numerical Lifting Line Theory Applied to Drooped Leading-Edge Wings Below and Above 
Stall," Journal of Aircraft, Vol. 17, No. 12, 1980, pp. 898-904. doi:10.2514/3.44690

[87] Spellucci, P., DONLP2 Users Manual, Technical Univ. at Darmstadt, Darmstadt, Germany, 1988.

[88] Ansys ${ }^{\circledR}$ Release 8.0 Theory: Reference Guide, ANSYS, Inc., Canonsburg, PA, Nov. 2003.

[89] Malvern, L. E., Introduction to the Mechanics of a Continuous Medium, Prentice-Hall, Upper Saddle River, NJ, 1969.

[90] Kaliske, M., and Rothert, H., "On the Finite Element Implementation of Rubber-Like Materials at Finite Strains," Engineering Computations: International Journal for Computer-Aided Engineering, Vol. 14, No. 2,
1997, pp. 216-232.

[91] van den Bogert, P., and de Borst, R., "On the Behavior of Rubberlike Materials in Compression and Shear," Archive of Applied Mechanics, Vol. 64, No. 2, 1994, pp. 136-146.

[92] Miller, K., Testing Elastomers for Hyperelastic Material Models in Finite Element Analysis, Vol. 3, Axel Products, Ann Arbor, MI, 2004.

[93] Raymer, D. P., Aircraft Design: A Conceptual Approach, 4th ed., AIAA Education Series, AIAA, Reston, VA, 2006, p. 460.

A. Messac Associate Editor 